Check for updates

Cite this: RSC Adv., 2019, 9, 11341

Received 28th January 2019

Accepted 28th March 2019

DOI: 10.1039/c9ra00761j

rsc.li/rsc-advances

\section{Different diameters of titanium dioxide nanotubes modulate Saos-2 osteoblast-like cell adhesion and osteogenic differentiation and nanomechanical properties of the surface $\dagger$}

\author{
Barbora Voltrova, (D) ab Vojtech Hybasek, (D) ${ }^{c}$ Veronika Blahnova, (D) ad \\ Josef Sepitka, (D) Vera Lukasova, (D) ab Karolina Vocetkova, (D) ad Vera Sovkova, (D) ad \\ Roman Matejka, iD f Jaroslav Fojt, (D) c Ludek Joska, (D c Matej Daniel (D) e \\ and Eva Filova iD *ad
}

The formation of nanostructures on titanium implant surfaces is a promising strategy to modulate cell adhesion and differentiation, which are crucial for future application in bone regeneration. The aim of this study was to investigate how the nanotube diameter and/or nanomechanical properties alter human osteoblast like cell (Saos-2) adhesion, growth and osteogenic differentiation in vitro. Nanotubes, with diameters ranging from 24 to $66 \mathrm{~nm}$, were fabricated on a commercially pure titanium (cpTi) surface using anodic oxidation with selected end potentials of $10 \mathrm{~V}, 15 \mathrm{~V}$ and $20 \mathrm{~V}$. The cell response was studied in vitro on untreated and nanostructured samples using a measurement of metabolic activity, cell proliferation, alkaline phosphatase activity and qRT-PCR, which was used for the evaluation of osteogenic marker expression (collagen type I, osteocalcin, RunX2). Early cell adhesion was investigated using SEM and ELISA. Adhesive molecules (vinculin, talin), collagen and osteocalcin were also visualized using confocal microscopy. Moreover, the reduced elastic modulus and indentation hardness of nanotubes were assessed using a Tribolndenter ${ }^{\mathrm{TM}}$. Smooth and nanostructured cpTi both supported cell adhesion, proliferation and bone-specific mRNA expression. The nanotubes enhanced collagen type I and osteocalcin synthesis, compared to untreated $\mathrm{cpTi}$, and the highest synthesis was observed on samples modified with $20 \mathrm{~V}$ nanotubes. Significant differences were found in the cell adhesion, where the vinculin and talin showed a dot-like distribution. Both the lowest reduced elastic modulus and indentation hardness were assessed from $20 \mathrm{~V}$ samples. The nanotubes of mainly $20 \mathrm{~V}$ samples showed a high potential for their use in bone implantation.

\section{Introduction}

In recent years, improvement of the biocompatibility and osseointegration of metal implants has become a challenging

${ }^{a}$ Department of Tissue Engineering, Institute of Experimental Medicine of the Czech Academy of Sciences, Vídeňská 1083, 14220 Prague 4, Czech Republic. E-mail: eva. filova@iem.cas.cz; Tel: +420 296442387

${ }^{b}$ Charles University in Prague, Faculty of Science, Albertov 2038/6, 128 oo Prague, Czech Republic

'Department of Metals and Corrosion Engineering, University of Chemistry and Technology, Technická 5, 16629 Prague, Czech Republic

${ }^{d}$ Charles University in Prague, Second Faculty of Medicine, V Úvalu 84, 15006 Prague, Czech Republic

${ }^{e}$ Department of Mechanics, Biomechanics and Mechatronics, Faculty of Mechanical Engineering, Czech Technical University in Prague, Technická 4, 16629 Prague, Czech Republic

${ }^{f}$ Faculty of Biomedical Engineering, Czech Technical University in Prague, Sportovcu 2311, 27201 Kladno, Czech Republic

$\uparrow$ Electronic supplementary information (ESI) available. See DOI: $10.1039 / \mathrm{c} 9 \mathrm{ra} 00761 \mathrm{j}$ task for biomaterial engineers. The most common material used for implants in orthopaedic surgery, dental reconstruction and prostheses is titanium. ${ }^{\mathbf{1 , 2}}$ Titanium and its alloys have been used because of their low toxicity, biocompatibility and appropriate mechanical properties. Commercially pure titanium (cpTi) is considered to be of very high standard for big joint implants. However, the inadequate osseointegration of smooth cpTi materials and the formation of a fibrous connective tissue layer on the bone-implant interface remain complicated in orthopaedic applications. To overcome these issues, a surface of titanium and its alloys has been widely modified to support cell adhesion and to encourage the formation of new bone on the interface between the implant surface and bone tissue. ${ }^{3}$ As was previously described, titanium dioxide $\left(\mathrm{TiO}_{2}\right)$ nanotube surfaces can accelerate recovery, improve bone-implant connection and enhance calcium and phosphorus deposition. ${ }^{4-6}$ Different methods were applied on the implant surfaces in order to prepare micro- or nanostructures, e.g. anodic oxidation, ${ }^{7}$ hydroxyapatite deposition, ${ }^{\mathbf{8}, 9}$ etching, ${ }^{\mathbf{1 0}}$ laser texturing, ${ }^{\mathbf{1 1}, \mathbf{1 2}}$ 
ultrasonic nanocrystal surface modification, ${ }^{13}$ and induction heating treatment. ${ }^{14}$ Carbon nanotubes (CNTs) provide another approach to nanostructured modification of the surfaces, providing a hollow geometry with a diameter of units or tens of nm, large specific area, high strength and toughness, thermal and electrical conductivity, and good bioactivity. ${ }^{15,16}$

Anodic oxidation is a widely used technique, because it is simple and highly effective. The anodization process in a fluorine-containing electrolyte, leads to the formation of vertically oriented $\mathrm{TiO}_{2}$ nanotubes with defined physical and chemical properties. These porous columnar structures, created from anodic oxides on metal titanium, were first reported by Zwilling et al. in 1999. ${ }^{17}$ Since then, anodic oxidation has become an effective and reproducible method to form nanotubes with defined length, inner and outer diameter on titanium-based biomaterials. It is also beneficial for tissue engineering application that the morphology and the diameter of nanotubes can easily be adjusted by a change of anodization parameters such as applied voltage, time of the modification or electrolyte composition and temperature. ${ }^{18}$

There have been several studies concerning the effect of $\mathrm{TiO}_{2}$ nanotubes on different titanium alloys to cell adhesion, differentiation and growth. Nanotubes with a diameter in the range of 15-100 $\mathrm{nm}$ have particularly been used for in vitro and in vivo studies of cell response and osseointegration.,19

Research has also shown, that $\mathrm{TiO}_{2}$ nanotubes provide a promising approach to preventing bacterial infection, as they enable the application of localized drug delivery systems. ${ }^{20}$ Earlier studies reported improved antibacterial properties after the incorporation of antibiotics, ${ }^{21} \mathrm{ZnO}^{22}$ or $\mathrm{Ag}^{23}$ into $\mathrm{TiO}_{2}$ nanotubes. The results from the above-mentioned studies clearly sustain nanotube modification as a suitable technique how to improve osseointegration and antibacterial properties of orthopaedic and dental implants. Despite extensive studies of cell behaviour on nanotubes with different diameters, there is still some discrepancies over nanotube size for optimal bone cell adhesion, growth and differentiation.

Among all the other properties of $\mathrm{TiO}_{2}$ nanostructures, elastic modulus $(E)$ is a property that affects directly the implant stability. It is desirable that the metal elastic modulus be as close as possible from that of the bone, because lower differences between the $E$ values result in better transfer of stress, avoiding stress-shielding effect. ${ }^{24}$

Elastic modulus and hardness of $\mathrm{TiO}_{2}$ nanotubes layer is not well established until now and it plays an important role in the long term stability of the implant, although few researches have investigate it in the past. Nanoindentation is the most suitable technique to determine the elastic modulus of such thin $\mathrm{TiO}_{2}$ oxide layer. Crawford has examined the deformation behavior of a nanotube layer using nanoindentation tests with a Berkovich probe, what led to an indentation penetration higher than the thickness of the nanotube layer and wear marks on indentation. ${ }^{25}$

This study focuses on the effect of $\mathrm{TiO}_{2}$ nanotubes of different diameters, created on cpTi surface, on osteoblast-like cells (Saos-2) growth, adhesion and osteoblastic differentiation in vitro.

\section{Materials and methods}

\section{Preparation of titanium specimens}

Commercially pure titanium (cpTi), grade 2, samples of $15 \mathrm{~mm}$ diameter and $3 \mathrm{~mm}$ height were used for nanostructuring. The specimens were wet-ground and polished up to mirror look. The nanostructuring was then realized with the potentiostatgalvanostat IMP 88 PC-200V with PGU-AUTO Extern control unit (Jaissle, IPS Elektroniklabor GmbH \& Co. KG, Germany). All anodization experiments were carried out at room temperature in an electrolyte containing glycerol $: \mathrm{H}_{2} \mathrm{O}: \mathrm{NH}_{4} \mathrm{~F}$ in weight ratio $65: 33: 2$ using a standard three electrode setup with glassy carbon rod as a counter electrode, the sample as the working electrode and a silver/silver chloride $\left(3 \mathrm{~mol} \mathrm{~L}^{-1} \mathrm{KCl}\right)$ reference electrode (SSCE). All presented potentials are related to this electrode. The electrochemical measurement consisted of a potential ramp from an open circuit potential to the selected end potential $(10 \mathrm{~V}, 15 \mathrm{~V}, 20 \mathrm{~V})$ with a $100 \mathrm{mV} \mathrm{s}^{-1}$ sweep rate and potentiostatic exposure for $1700 \mathrm{~s}, 1650 \mathrm{~s}$ and $1600 \mathrm{~s}$ for $10 \mathrm{~V}, 15 \mathrm{~V}$ and $20 \mathrm{~V}$ respectively. A potentiodynamic decrease with a potential of $0 \mathrm{~V}$ and polarization rate $-100 \mathrm{mV} \mathrm{s}^{-1}$ then followed. A decrease of the potential at the end of the anodization, led to the creation of a compact oxide interlayer between the tubes and the metal. This layer was approximately $100 \mathrm{~nm}$ thick and increased the adhesion of the nanostructure to the base material. After the electrochemical measurement, the samples were ultrasonicated in ethanol and deionized water and then dried in air stream. Untreated cpTi was used as the control (Ti).

\section{Surface characterization of the specimens}

For the morphological characterization of samples, a Vega3 scanning electron microscope (SEM) (Tescan, Czech Republic) was used. The length and inner diameter of the nanotubes was evaluated from SEM images in ImageJ software. The data from four distant image fields, from at least four samples were used for analysis.

\section{Sterilization of the samples}

Titanium disks were sterilized in $70 \%$ ethanol, for $30 \mathrm{~min}$ in room temperature, after washed three times with PBS and transferred to nonadherent 24-well plate (non-treated surface, Corning ${ }^{\circledR}$ Costar ${ }^{\circledR}$, USA). The same procedure was used for glass coverslip.

\section{Cell seeding}

Saos-2 cells (passage 88, CLS Cell Lines Service GmbH, Germany) were seeded on cpTi scaffolds at the density $1.5 \times 10^{4}$ cells per $\mathrm{cm}^{-2}$. Similarly, cells were seeded on glass coverslip and cultured in McCoy's 5A medium (Sigma-Aldrich, USA) supplemented with 15\% foetal bovine serum (Gibco; Thermo Fisher Scientific, Waltham, MA, USA), ascorbate-2 phosphate (40 $\mu \mathrm{g} \mathrm{mL}{ }^{-1}$, Sigma-Aldrich), penicillin/streptomycin (100 IU $\mathrm{mL}^{-1}, 100 \mu \mathrm{g} \mathrm{mL}{ }^{-1}$, Sigma-Aldrich). For ELISA $4 \times 10^{4}$ cells per well were seeded on each sample and cultured in a nonadherent 
24-well plate (Costar). The medium was changed twice weekly; all samples were prepared in triplicate, for enzyme-linked immunosorbent assay (ELISA) in pentaplicate.

\section{Quantification of vinculin and talin}

The concentration of focal adhesion proteins (vinculin and talin) was determined using the enzyme-linked immunosorbent assay (ELISA). For ELISA measurement Saos-2 were seeded as described in the section cell seeding. To standardize the obtained concentration of the focal adhesion proteins, the amount of total protein in the cells was determined using Quant-iT protein assay kit (Thermo Fisher Scientific) according to the manufacturer's instructions, and the concentration of the focal adhesion proteins was related to the $\mathrm{mg}$ of total protein contained in the cells. The cells were harvested after $24 \mathrm{~h}$ of culture, suspension was centrifuged and frozen in PBS. The cell homogenates were prepared by ultrasonication for $30 \mathrm{~s}$ (amplitude $70 \%, 24 \mathrm{kHz}$ ) using the ultrasonic homogenizer (model $300 \mathrm{~V} / \mathrm{T}$, BioLogics, Inc., USA) on ice. The concentration of vinculin and talin in the cell homogenates was determined using the FineTest ELISA kits (FineTest, China) as per manufacturer's instructions. The absorbance was read using a Synergy HT microplate reader (BioTek, USA).

\section{Cell adhesion evaluation using confocal microscopy}

Saos- 2 cells were seeded as described in cell seeding. Two days after seeding, the cells were fixed with $4 \%$ paraformaldehyde for 5 min, washed once with PBS and stored in PBS at $2-8{ }^{\circ} \mathrm{C}$ before staining. The samples were then washed three times with PBS and incubated in $3 \% \mathrm{FBS} / 0.1 \%$ Triton $\mathrm{X}$ in $\mathrm{PBS}$ for $30 \mathrm{~min}$ at room temperature. The samples were then incubated with $1 \%$ Tween 20 in PBS for $20 \mathrm{~min}$ at room temperature. A monoclonal antibody against talin was applied (dilution $1: 200$, clone 8d4, ascites fluid, T3287, Sigma-Aldrich) or vinculin (dilution $1: 100$, monoclonal hVIN-1, product V9131, Sigma-Aldrich) overnight at $2-8{ }^{\circ} \mathrm{C}$. After being washed three times with PBS/0.05\% Tween (3, 5, $10 \mathrm{~min})$ and once in PBS, anti-mouse secondary antibody, conjugated with Goat anti-Mouse IgG/IgA/IgM (H + L) AlexaFluor 488 (dilution $1: 300$, A10667, Invitrogen Life Technologies, USA), was added for $45 \mathrm{~min}$ at room temperature. Subsequently, after the same washing procedure, the samples were incubated with Phalloidin conjugated with ATTO-633 (dilution $20 \mu \mathrm{L} / 1 \mathrm{~mL}$ PBS, Sigma-Aldrich) for 1 hour at room temperature. Cell nuclei were counterstained with Hoechst 34580 ( $1: 5000, \mathrm{H} 21486$, Life Technologies) for $30 \mathrm{~min}$ at RT and washed twice in PBS. The samples were scanned using confocal microscope ZEISS LSM 5 DUO at $\lambda_{\mathrm{ex}}=405 \mathrm{~nm}, \lambda_{\mathrm{em}}=$ $420-460 \mathrm{~nm}$ for Hoechst, $\lambda_{\text {exc }}=488 \mathrm{~nm}$ and $\lambda_{\text {em }}=505-550 \mathrm{~nm}$ for Alexa Fluor $488, \lambda_{\mathrm{ex}}=633 \mathrm{~nm}, \lambda_{\mathrm{em}}>650 \mathrm{~nm}$ for ATTO-633 staining.

\section{Cell visualization using scanning electron microscopy}

SEM was used to visualize the cells adhered on the scaffolds 2 days after seeding. For the visualization, two samples per group were used. The samples were washed with PBS and fixed with $2.5 \%$ glutaraldehyde (Sigma-Aldrich) for $2 \mathrm{~h}$ at $4{ }^{\circ} \mathrm{C}$. Fixed samples were then dehydrated with ethanol series (35\%, 48\%, $70 \%, 96 \%$ and twice at 100\%). Hexamethyldisilazane (SigmaAldrich) was used to remove residual water from the samples. The samples were sputter-coated with gold ( $3 \mathrm{~nm}$ ) and visualized using Vega 3 SBU microscope (Tescan).

\section{Cell proliferation}

Cell proliferation was measured using Quant-iT'T dsDNA Assay Kit (Life Technologies). The samples were washed twice with PBS and put into $500 \mu \mathrm{L}$ lysate buffer $(0.2 \% \mathrm{v} / \mathrm{v}$ Triton X-100, $10 \mathrm{mM}$ Tris (pH 7.0) and $1 \mathrm{mM}$ EDTA). The samples were frozen/thawed in three cycles $\left(-80{ }^{\circ} \mathrm{C} /\right.$ room temperature). The amount of dsDNA was evaluated according to the manufacturer's instructions using a multidetection reader Tecan Infinite ${ }^{\circledR}$ M200 Pro, $\lambda_{\text {ex }}=485 \mathrm{~nm}, \lambda_{\text {em }}=523 \mathrm{~nm}$.

\section{Metabolic activity}

Metabolic activity of Saos-2 was evaluated using an MTS test (CellTiter 96® AQueous One Solution Cell Proliferation Assay, Promega, USA) on days $1,4,7$, and 11 . Scaffolds were transferred to new wells, incubated with $300 \mu \mathrm{L}$ media and $60 \mu \mathrm{L}$ MTS solution for $2 \mathrm{~h}$ at $37{ }^{\circ} \mathrm{C}, 5 \% \mathrm{CO}_{2}$. Subsequently, $100 \mu \mathrm{L}$ of the metabolized solution from each well was put into a 96-well plate and the absorbance was measured at $490 \mathrm{~nm}\left(\lambda_{\text {ref }}=690\right.$ $\mathrm{nm}$ ) using reader Tecan Infinite ${ }^{\circledR}$ M200 Pro (Tecan Trading AG, Switzerland).

\section{Real time PCR}

RNA was isolated from three samples per group on days 1, 7, and 11 using the RNeasy Mini Kit (Qiagen, Germany) following the manufacturer's instructions. The RNA content and ratio of absorbance at $260 \mathrm{~nm}$ to $280 \mathrm{~nm}$, was measured using Tecan Infinite ${ }^{\circledR}$ M200 Pro reader. The result of this procedure indicates the purity and amount of RNA in nanograms per sample. The presence of DNA in the samples was checked using standard agarose gel electrophoresis. For the cDNA synthesis RevertAid H Minus First Strand cDNA Synthesis Kit (Thermo Scientific, USA) was used. The isolated mRNA was transcribed to cDNA by reverse transcription; during the procedure samples were stored on ice. Thereafter, genes were analysed for osteogenic marker RunX2, collagen type I, osteocalcin and EEF1 gene (eukaryotic elongation factor) which was used as a housekeeping gene. Fluorescence values for osteogenic genes were normalized by EEF1 values. The cDNA was used to perform RTPCR with the reaction parameters as follows: activation $-95^{\circ} \mathrm{C}$, $10 \mathrm{~min}$; amplification $-95^{\circ} \mathrm{C}$ for $10 \mathrm{~s}, 60^{\circ} \mathrm{C}$ for $10 \mathrm{~s}$ (50 cycles); termination $-40{ }^{\circ} \mathrm{C}$ for $1 \mathrm{~min}$. The TaqMan probes with a fluorescent label at the $5^{\prime}$ end and the quencher on the $3^{\prime}$ end (reviewed in Table 1) was used to detect the amount of copied sequences of interest. The TaqMan Gene Expression Master Mix (Thermo Scientific) and RT-PCR Grade Water (Thermo Scientific) was added to each sample. mRNA levels for each gene were relatively quantified using housekeeping gene EEF1. Graphs were generated from the values obtained by calculation according to the formula $2^{-\Delta C_{\mathrm{p}}}$. In between the isolation of RNA, cDNA synthesis and RT-PCR, samples were stored in a freezer at 
Table 1 List of analysed genes with their codes and catalogue numbers $^{a}$

\begin{tabular}{lll}
\hline Gene name & Code & Catalogue No. \\
\hline EEF1 & Hs00265885_g1 & 4331182 \\
RunX2 & Hs00231692_m1 & 4331182 \\
OCN & Hs01587814_g1 & 4331182 \\
ColI & Hs01028969_m1 & 4331182
\end{tabular}

${ }^{a}$ EEF1 - eukaryotic elongation factor-1; RunX2 - Runt-related transcription factor 2; OCN - osteocalcin; COlI - collagen type I.

$-80^{\circ} \mathrm{C}$. To measure the fluorescence intensity, Light Cycler 480 (Roche, Switzerland) was used.

\section{Alkaline phosphatase (ALP) activity measurement}

ALP activity was measured using a 1-Step ${ }^{\mathrm{TM}}$ PNPP kit (Thermo Fisher Scientific) from three samples per group. Culture medium was removed from the wells and washed twice with a phosphate buffered saline (PBS). Each scaffold was incubated with $350 \mu \mathrm{L} p$-nitrophenyl phosphate (pNPP) for $5 \mathrm{~min}$ at room temperature. Subsequently, the reaction was stopped with 175 $\mu \mathrm{L} 2 \mathrm{M} \mathrm{NaOH}$. The absorbance of $100 \mu \mathrm{L}$ of the ALP solution was measured in a 96-well plate after $1: 1$ dilution with PBS at $405 \mathrm{~nm}$ using reader Tecan Infinite ${ }^{\circledR}$ M200 Pro.

\section{Immunohistochemical staining of collagen type I and osteocalcin}

Three samples per group including glass as a control were fixed with frozen methanol, washed with PBS and incubated in $3 \%$ FBS in $\mathrm{PBS} / 0.1 \%$ Triton for $30 \mathrm{~min}$ at room temperature. A primary monoclonal antibody against osteocalcin (T-4743, Peninsula Laboratories, USA, dilution $1: 20$ ) or collagen type I (M-38c, DSHB, USA, dilution $1: 20$ ) was added, and the samples were incubated overnight at $4{ }^{\circ} \mathrm{C}$. After three washes with PBS/ $0.05 \%$ Tween, and once with PBS the samples were incubated with secondary antibody, Alexa Fluor 488-conjugated antirabbit or anti-mouse antibody, for $45 \mathrm{~min}$, dilution 1 : 300 (Life Technologies). The cell nuclei were stained with $5 \mu \mathrm{g} \mathrm{mL}^{-1}$ propidium iodide (PI) in PBS for $10 \mathrm{~min}$ (Sigma-Aldrich). The cells were visualized using a confocal microscope ZEISS LSM 5 DUO at $\lambda_{\text {exc }}=488 \mathrm{~nm}$ and $\lambda_{\text {em }}=505-550 \mathrm{~nm}$ for Alexa Fluor 488 and $\lambda_{\mathrm{ex}}=560 \mathrm{~nm}, \lambda_{\mathrm{em}}>575 \mathrm{~nm}$ for PI. All the samples were scanned in one experimental day per each protein, using the same setup during that day. The total fluorescence intensity of osteocalcin, or collagen type I per cell was analysed using Fluorescent Image Analysis Software (version 1.0). ${ }^{\mathbf{2 6}}$

\section{Statistical analysis}

The obtained data were statistically analysed using SigmaStat 3.5 software. Quantitative data are presented as mean values \pm standard deviation (SD). Prior to measurement, normality was evaluated. Results were evaluated statistically using one-way analysis of variance (ANOVA), Student-Newman-Keuls method was used for post hoc analysis with a significance value of less than 0.05. Values were determined from at least 3 samples.

\section{Nanomechanical properties}

A Hysitron TI 950 TriboIndenter ${ }^{\mathrm{TM}}$ nanomechanical test instrument was used for an assessment of depth profiles of mechanical properties on titanium dioxide nanostructures $(10 \mathrm{~V}, 15 \mathrm{~V}$ and $20 \mathrm{~V})$. Depth profiles were investigated using the partial unloading function $\left(P_{\max }=10000 \mu \mathrm{N}, 33\right.$ cycles consisted of loading, dwell, and unloading segments, each lasting 1 second) with Berkovich diamond tip. ${ }^{27,28}$ Partial unload approach requires elastic-plastic deformation during gradual force cycles in order to analyse each unloading segment according Oliver \& Pharr method. ${ }^{29}$ Automated analysis plots the depth profile as discrete datasets.

\section{Results}

Anodic oxidation was successfully used for the preparation of nanostructures on cpTi. Nanotubes with a diameter in the range 24-66 nm, with length approximately $468 \mathrm{~nm}(10 \mathrm{~V})$ up to $1097 \mathrm{~nm}(20 \mathrm{~V})$ were created, using a different applied potential. Histograms of nanotube diameter and scanning electron microscopy (SEM) photomicrographs for each modified sample are summarized in Fig. 1. Inner diameter and length of the nanotubes were successfully evaluated. The tubes length was measured from the tubes side view micrographs. Basic characterization of the samples is specified in Table 2.

We have tested untreated cpTi (Ti), and nanostructured cpTi scaffold prepared using potential $10 \mathrm{~V}, 15 \mathrm{~V}$ and $20 \mathrm{~V}$ in vitro. Glass coverslip was used as a control group. Saos- 2 cell proliferation, metabolic activity and differentiation, e.g. production of collagen type I and osteocalcin, ALP activity was investigated. As well as mRNA expression of osteocalcin, collagen type I and RunX2 were examined in Saos-2 on all surfaces.

ELISA was performed for quantification of the vinculin and talin synthetized in Saos- 2 one day after cell seeding. The concentration of vinculin increased on nanostructured samples, when the highest concentration was measured on $20 \mathrm{~V}$ (Fig. 2A). On the contrary, concentration of talin was significantly higher on $\mathrm{Ti}, 10 \mathrm{~V}, 15 \mathrm{~V}$ and glass, compared to $20 \mathrm{~V}$ with the biggest nanotube diameter (Fig. 2B). The highest amount of talin was on a flat surface of glass.

In addition, the presence of focal adhesion molecules (vinculin, talin), synthetized by Saos- 2 on a differently treated cpTi surface, were visualized using confocal microscopy $48 \mathrm{~h}$ after seeding. Fig. 3 describes the homogenous dot-like positive signals of adhesive molecules on nanotube and smooth surfaces. On glass and Ti the signal was differently organized, with the greatest signal on ends of the cells with line like morphology corresponding to focal complexes formed at the cells periphery.

On smooth surfaces of untreated $\mathrm{Ti}$ and glass dense positive vinculin areas were colocalized with the ends of F-actin stress fibres (Fig. 3A and E). Talin shows a continuous distribution in cytoplasm, with stronger signal on the edges of the cells 
$10 \mathrm{~V}$

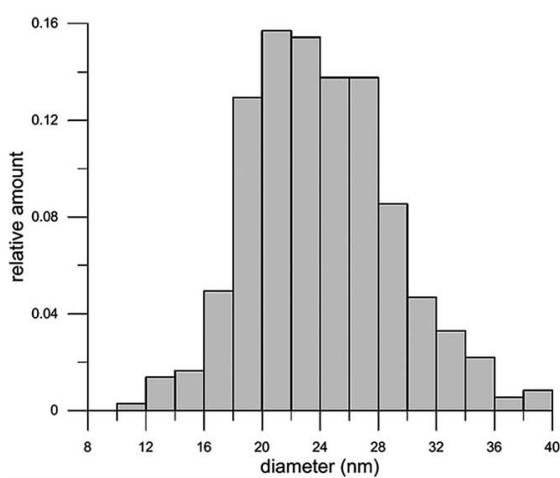

$15 \mathrm{~V}$

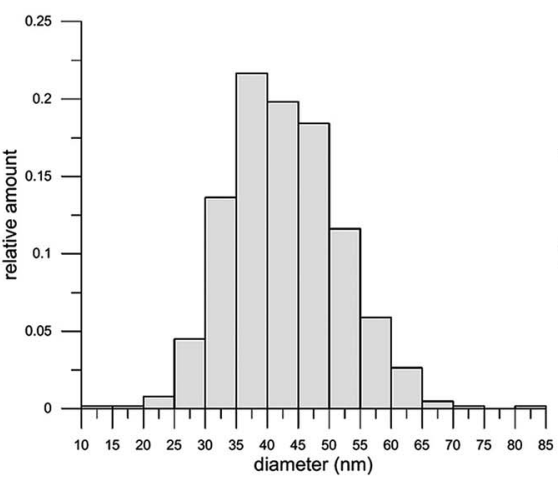

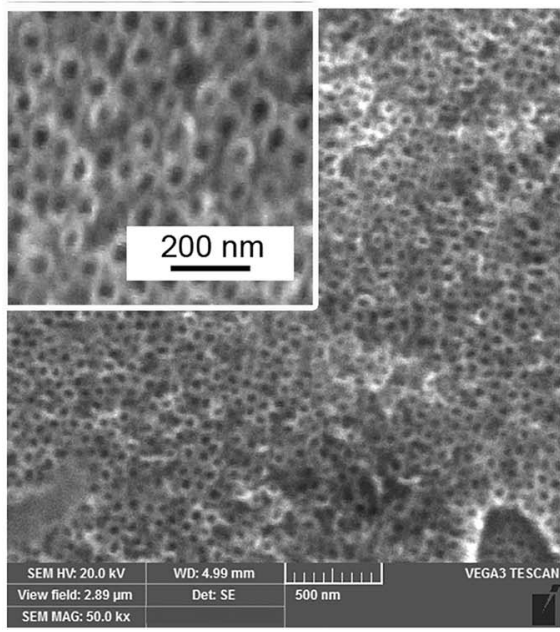
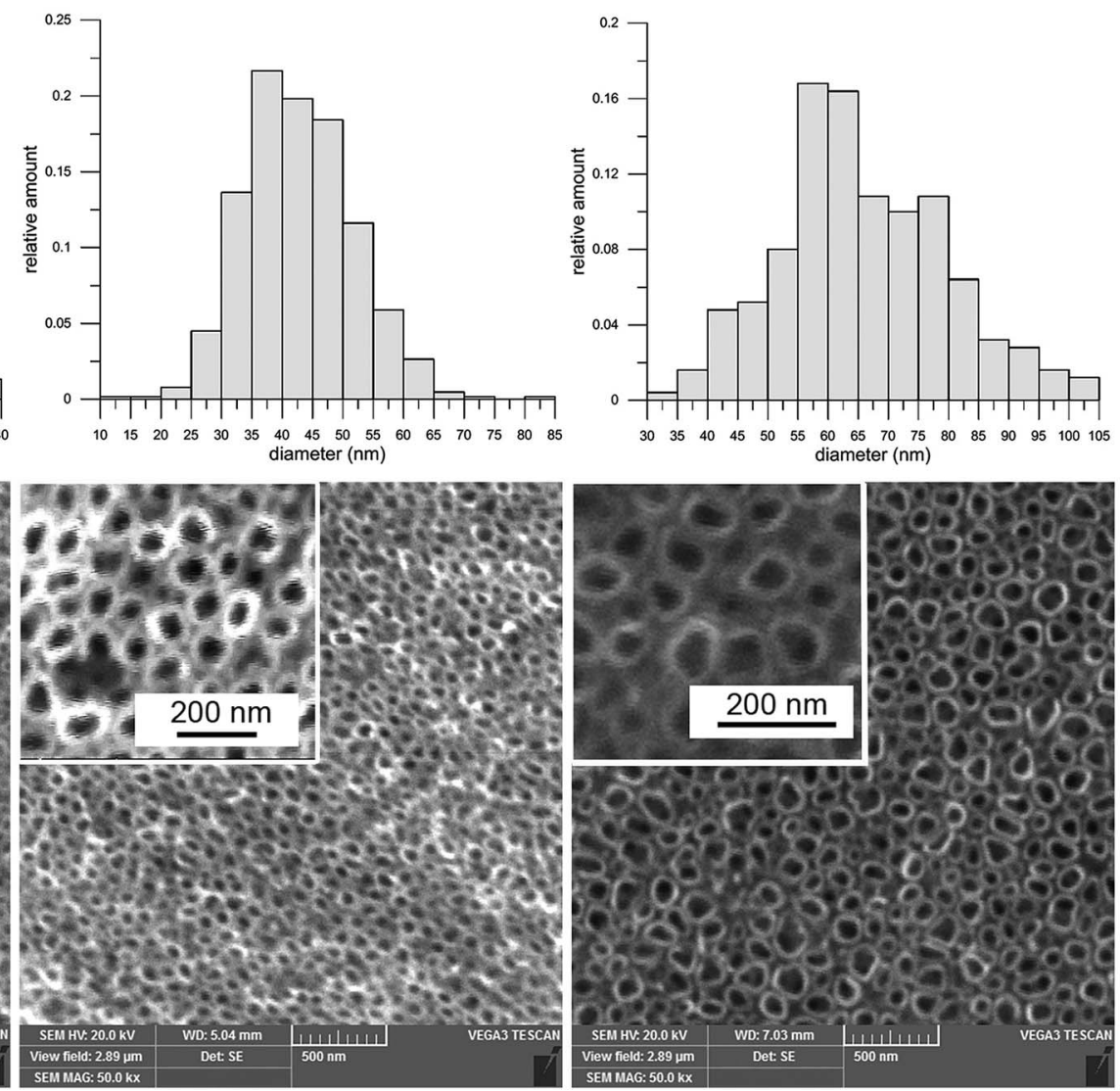

Fig. 1 Histograms of nanotube inner diameters and scanning electron microscopy visualization of nanostructures, created by anodic oxidation at $10 \mathrm{~V}, 15 \mathrm{~V}, 20 \mathrm{~V}$ on cpTi. Magnification $50 \mathrm{k} \times$.

Table 2 Diameter and length of $\mathrm{TiO}_{2}$ nanotubes on cpTi prepared by anodic oxidation under specific applied potential ${ }^{a}$

\begin{tabular}{llr}
\hline $\begin{array}{l}\text { Applied potential } \\
{[\mathrm{V}]}\end{array}$ & $\begin{array}{l}\text { Diameter of nanotubes } \\
(\mathrm{nm} \pm \mathrm{SD})\end{array}$ & $\begin{array}{l}\text { Length of nanotubes } \\
(\mathrm{nm} \pm \mathrm{SD})\end{array}$ \\
\hline 10 & $24 \pm 5$ & $468 \pm 24$ \\
15 & $43 \pm 9$ & $731 \pm 32$ \\
20 & $66 \pm 14$ & $1097 \pm 75$
\end{tabular}

${ }^{a} \mathrm{SD}$ - standard deviation, cpTi - commercially pure titanium.

cultured on glass (Fig. 3G-K). Saos-2 adhesion, $48 \mathrm{~h}$ after seeding describe the SEM images in Fig. 4. Cells were well spread on all scaffolds, with polygonal shape and developed filopodia. On nanostructured samples, the morphology was flatter than on glass coverslip and untreated cpTi.

Cell proliferation was high in all samples with no differences among nanostructured or control samples, see Fig. 5A. The highest dsDNA amount was measured at $10 \mathrm{~V}$. Additionally, cell visualization using live/dead staining, shows an increase in the Saos- 2 number in cultivation time and $100 \%$ living cells on all the samples. However, a decreased concentration of the cells at $10 \mathrm{~V}$ and $20 \mathrm{~V}$ were detected on day 11 compared to other samples.
The metabolic activity of Saos-2 (Fig. 5B) during the first four days did not differ among the samples. Contrariwise, samples $10 \mathrm{~V}$ and $20 \mathrm{~V}$ showed significantly higher absorbance compared to Ti on day 11. Higher absorbance values of MTS were obtained at $10 \mathrm{~V}, 20 \mathrm{~V}$ and glass compared to Ti on day 1. On day 4, Ti showed a higher absorbance than $15 \mathrm{~V}$. Moreover, glass showed a higher absorbance than $15 \mathrm{~V}$ and $20 \mathrm{~V}$ on day 4 . No significant differences were seen on day 7. Fig. 5(C-E) shows an osteogenic differentiation on titanium samples during 11 days of the cell culture. The high increase of osteocalcin mRNA was found on day 7 in all scaffolds where untreated cpTi showed significantly higher values than nanostructured cpTi samples. Moreover, on day 11 there was a statistically higher osteocalcin mRNA expression in groups $10 \mathrm{~V}$ and glass than in the group $20 \mathrm{~V}$. On the first experimental day there were no significant differences among the groups. As shown in Fig. 5(E), collagen type I mRNA expression was increased on days 7 and 11 in all samples and was significantly higher expressed on glass compared to groups $15 \mathrm{~V}, 10 \mathrm{~V}$ and Ti on day 7 . On day 11, the collagen type I expression was significantly higher on glass than in the $20 \mathrm{~V}$ samples. mRNA synthesis of RunX2, which is an early osteogenic marker, did not show any difference among samples. 
A

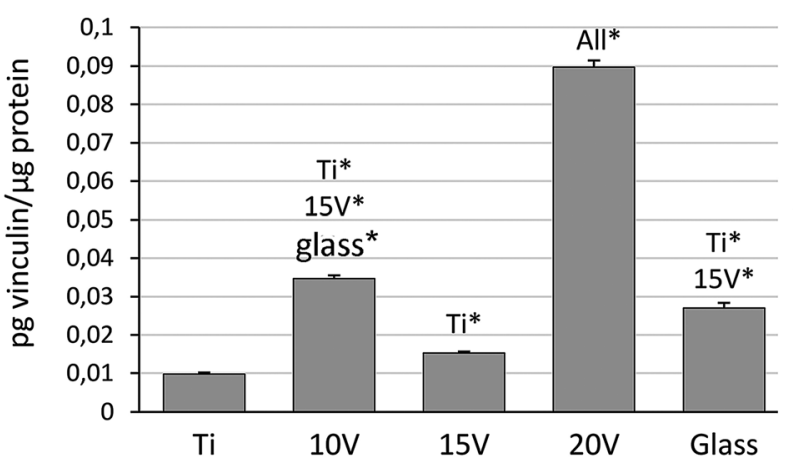

B

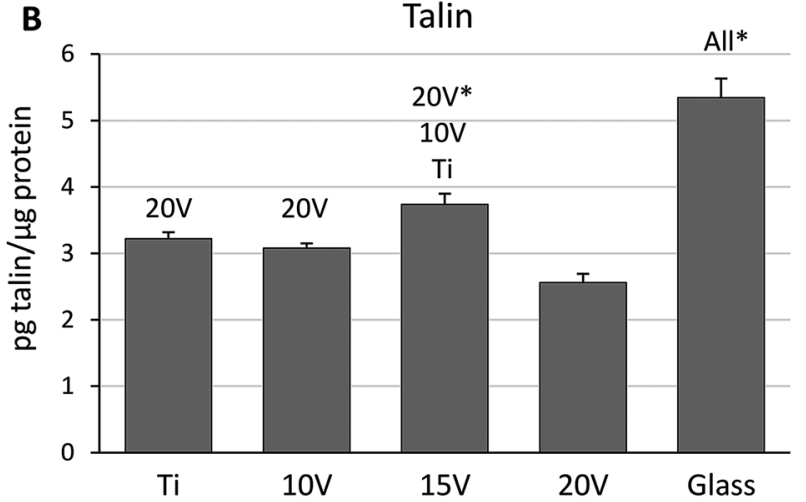

Fig. 2 Concentration of focal adhesion proteins, vinculin (A), talin (B), measured by the enzyme-linked immunosorbent assay (ELISA) in human Saos- 2 osteoblast-like cells cultured 24 hours on untreated cpTi, differently nanostructured cpTi by anodic oxidation at $10 \mathrm{~V}, 15 \mathrm{~V}, 20 \mathrm{~V}$ and control glass. $P$ values $<0.05$ (marked by group name) and $P<0.01$ (marked by group name and an asterisk) considered significant versus samples labelled above.

ALP, an early marker of osteogenic differentiation, showed a significantly higher activity of the enzyme on day 1 in the case of glass, compared to samples $10 \mathrm{~V}, 20 \mathrm{~V}$ (Fig. 6). Moreover, $15 \mathrm{~V}$ nanostructured cpTi showed a higher ALP than $10 \mathrm{~V}$. Synthesis of collagen type I and osteocalcin by Saos- 2 were analysed and calculated from 10 confocal photomicrographs per sample. On day 7 of culture, the fluorescence intensity of collagen type I, was significantly higher on all nanostructured scaffolds compared to control Ti and glass (Fig. 7). Equally, the fluorescence intensity was increased on nanotubes on day 11. The highest intensity was reached in both experimental days at $20 \mathrm{~V}$; moreover, the values were significantly higher compared to nanostructured surfaces $10 \mathrm{~V}$ and $15 \mathrm{~V}$. A similar trend was observed for osteocalcin intensity, where evidently the highest presence of osteocalcin was detected at $20 \mathrm{~V}$. In addition, sample $10 \mathrm{~V}$ also significantly differs from $15 \mathrm{~V}$ and untreated Ti. Similarly, illustrative confocal images in Fig. 8 show increased collagen type I on nanostructured samples, compared to control Ti and glass. Osteocalcin is commonly used as a late marker of osteogenic differentiation; therefore, it was visualised on the end of the experiment. On day 11, the osteocalcin positive areas were presented on all nanostructured and untreated $\mathrm{Ti}$; on the contrary a very low signal was detected on glass as is shown in Fig. 9.

Fig. 10 shows an influence of porosity to the mechanical properties. Mechanical properties decrease with increasing porosity of the titanium sample. Elastic modulus and hardness in the shallow depths correspond to the mechanical properties of human bone. There is evident increase of the mechanical properties with the contact depth. This is the influence of the titanium substrate to the measured nanotubes because of the $1 /$ 10 rule $^{30}$ The trend of measured data slowly going toward to the bulk cpTi (substrate) mechanical properties; reduced elastic modulus $E_{\mathrm{r}} \sim 98-107 \mathrm{GPa}$ and indentation hardness $H_{\mathrm{IT}} \sim 3-$ $5 \mathrm{GPa}^{31,32}$ Based on the rule $1 / 10$ and length of nanotubes in the Table 2 we can accept measured data up to the contact depth $h_{\mathrm{c}}$ $=46.7 \pm 2.4 \mathrm{~nm}$ for $10 \mathrm{~V}, h_{\mathrm{c}}=73.1 \pm 3.2 \mathrm{~nm}$ for $15 \mathrm{~V}$ and $h_{\mathrm{c}}=$ $109.7 \pm 7.5 \mathrm{~nm}$ for $20 \mathrm{~V}$. The data up to these depths are not affected by the cpTi substrate and represent mechanical properties of nanotubes. Minimum values of reduced elastic modulus $E_{\mathrm{r}}=19.58 \pm 8.83 \mathrm{GPa}$ and indentation hardness $H_{\mathrm{IT}}=$ $0.32 \pm 0.11 \mathrm{GPa}$ were obtained from sample $20 \mathrm{~V}$ respectively. Maximum values of reduced elastic modulus of nanotubes $E_{\mathrm{r}}=$ $31.59 \pm 9.24 \mathrm{GPa}$ and indentation hardness of nanotubes $H_{\mathrm{IT}}=$ $0.39 \pm 0.15 \mathrm{GPa}$ were obtained from sample $10 \mathrm{~V}$ respectively. $15 \mathrm{~V}$ has elastic modulus of nanotubes $E_{\mathrm{r}}=22.25 \pm 5.49 \mathrm{GPa}$ and indentation hardness of nanotubes $H_{\mathrm{IT}}=0.36 \pm 0.07 \mathrm{GPa}$.

\section{Discussion}

Titanium implant integration into bone is a multistep process involving cell adhesion, growth and differentiation, followed by extracellular matrix (ECM) production and mineralization. Therefore, it is important to design biomaterials which support the above-mentioned processes. Nanostructured titanium has become a promising modification for biomedical applications, where the nanotube-based implants have attracted considerable attention. It is believed, that a nanostructured surface better mimics the morphology and function of native bone tissue, and allows for the transport and exchange of metabolites, nutrients and gas. ${ }^{33}$ Furthermore, in comparison with the smooth surface of implants, a greater surface area of nanostructured titanium is beneficial for cell attachment, spreading and anchoring of their filopodia. ${ }^{34,35}$ Despite extensive studies of cell behaviour on nanotubes with different diameters, there is still some controversy over nanotube size for optimal osteoblast adhesion, growth and differentiation. ${ }^{36-40}$ Therefore, we investigated the effect of titanium nanotubes fabricated by anodic oxidation with various diameters $(24,43$ and $66 \mathrm{~nm})$ on osteoblast-like cell response. In this study, the human osteosarcoma cell line Saos-2 was chosen as an osteoblastic cell model for the nanostructured titanium system. This cell line has been widely used as in vitro model in bone tissue engineering because of its phenotype stability in prolonged cell passages, high mineralization capacity, bone ECM synthesis and similar behaviour to primary human osteoblasts. ${ }^{41-43}$ 

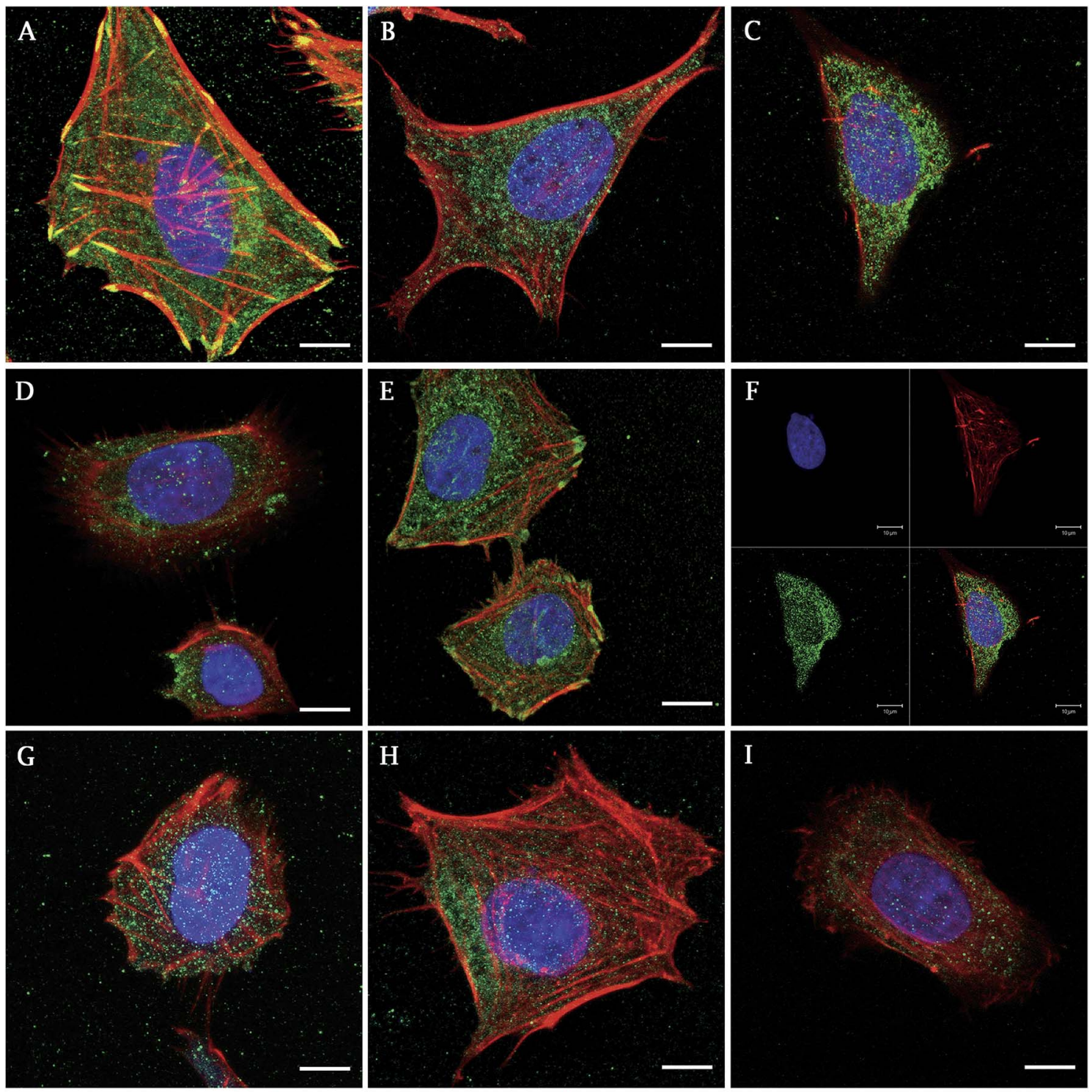

H
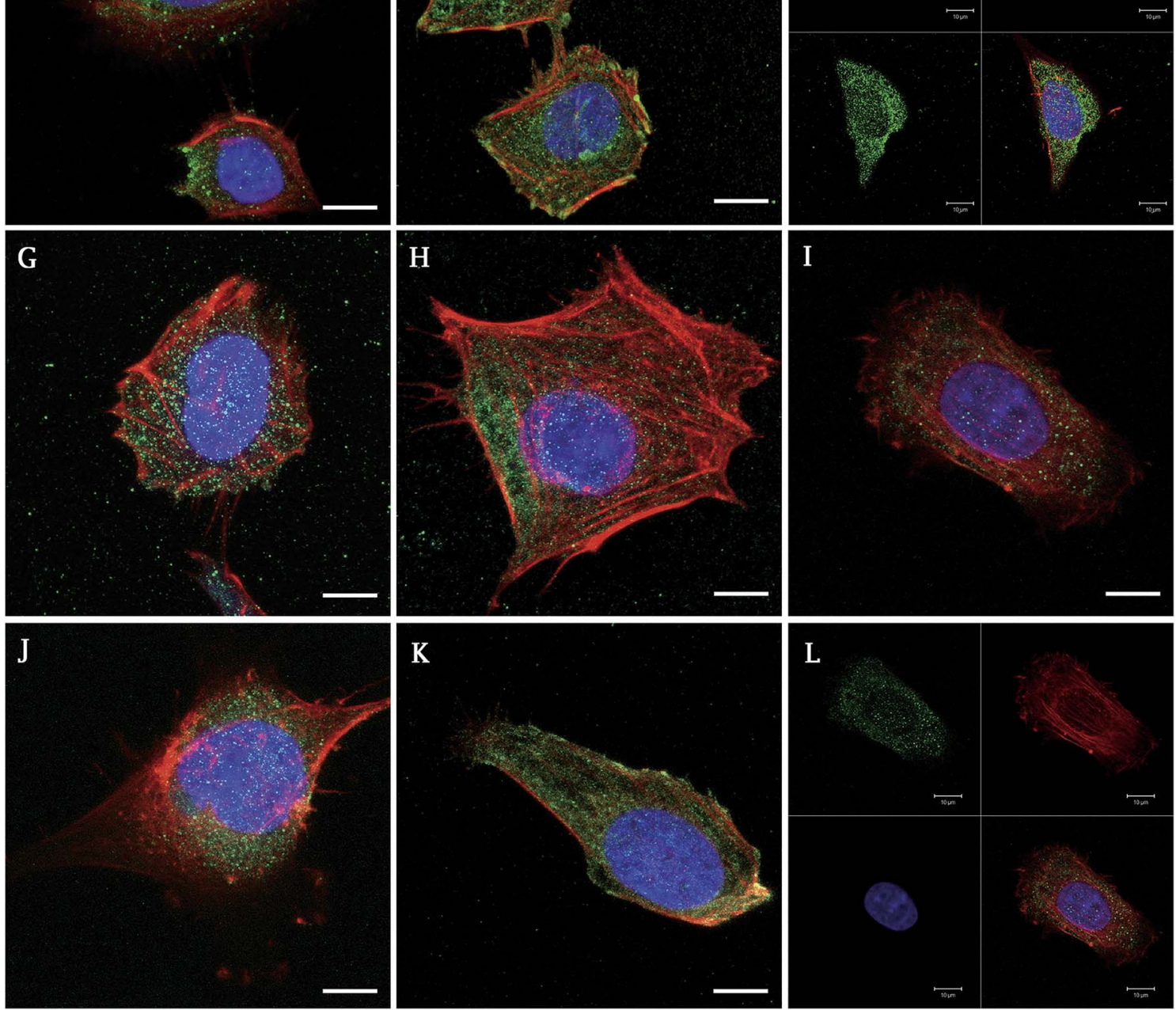

I

K

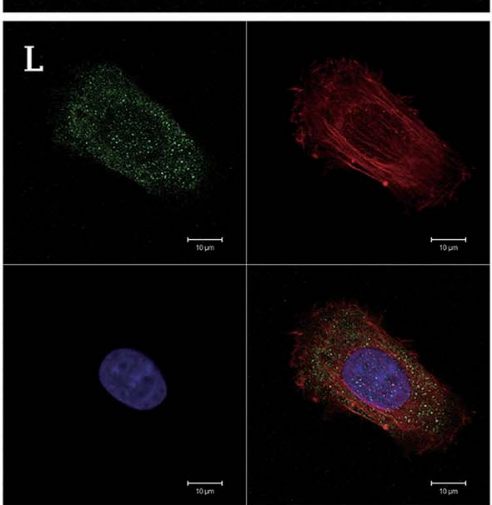

Fig. 3 Immunofluorescence staining of vinculin (A-F) and talin (G-L) in human Saos-2 osteoblast-like cells cultured on cpTi samples $48 \mathrm{~h}$ after seeding. Untreated cpTi (A and G), nanostructured cpTi by anodic oxidation at $10 \mathrm{~V}(\mathrm{~B}$ and H), $15 \mathrm{~V}(\mathrm{C}$ and $\mathrm{I}), 20 \mathrm{~V}(\mathrm{D}$ and $\mathrm{J})$ and control glass (E and K). Separated channels in photomicrographs of $15 \mathrm{~V}$ sample ( $\mathrm{F}$ and L). Vinculin and talin (green), F-actin (red) and nucleus (blue). Objective 63× , magnification $2 \times$, scale $20 \mu \mathrm{m}$, immerse oil.

The importance of enhancing initial cell adhesion on titanium implants has been the subject of several studies. Popat et $a l .{ }^{6}$ and later Das et al. ${ }^{44}$ proposed that osteoblasts anchor their filopodia inside $\mathrm{TiO}_{2}$ nanotubes. This theory was later proved by Shokuhfar et al., ${ }^{35}$ who used cross sections of SEM and FIB (focused ion beam) milling to visualize the evident 

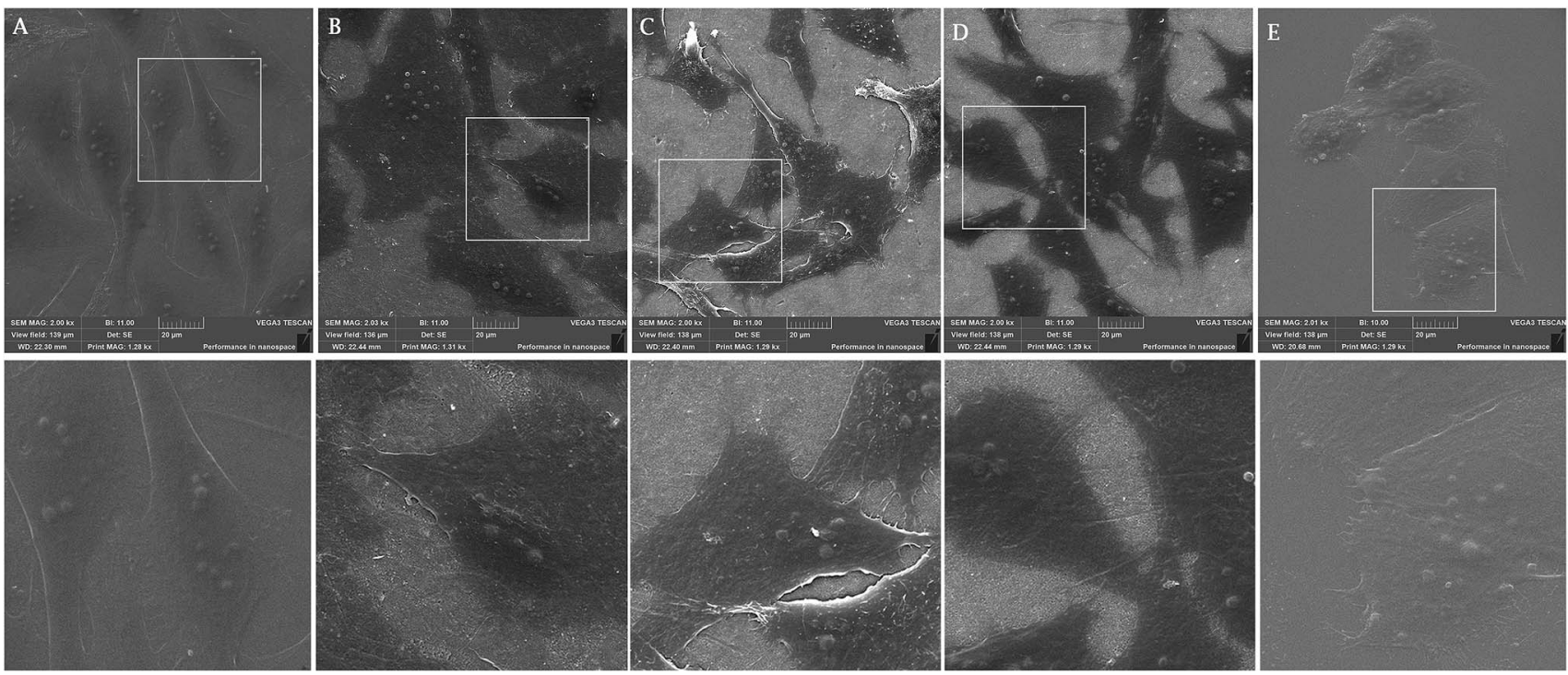

Fig. 4 Visualization of human Saos-2 osteoblast-like cells adhered on untreated and nanostructured cpTi scaffolds 48 hours after seeding, scanning electron microscopy. Cells cultured on untreated $\mathrm{cpTi}(\mathrm{A})$, nanostructured $\mathrm{cpTi}$ by anodic oxidation at $10 \mathrm{~V}(\mathrm{~B}), 15 \mathrm{~V}(\mathrm{C}), 20 \mathrm{~V}(\mathrm{D})$ and control glass (E). Magnification $2 \mathrm{k} \times$. The marked squares of SEM photographs of the upper row are magnified in a lower row.

interlock between osteoblasts and nanotubes created on cpTi using anodic oxidation, with a diameter of $100 \mathrm{~nm}$ and length of $1 \mu \mathrm{m}$. Additionally, they reported penetration of the cell filopodia inside the nanotubes on crystalline nanotubes, whereas on amorphous phase of the nanotubes, filopodia adhered on the nanotubes with little filling inside. ${ }^{35}$ The SEM images presented here show well spread Saos-2 cells on nanostructured samples with filopodia extended from the edge of the polygonal shaped cells. Spindle shaped cells were seen on a smooth cpTi surface. It is widely accepted that cell adhesion is affected by surface chemical properties, roughness, wettability and surface energy. These factors subsequently influence the adsorption of proteins (fibronectin, vitronectin) from media, respective body fluids, which are crucial for initial cell attachment via integrins. It has been suggested that the mechanism of osteoblasts adhesion on nanotube-based surfaces is facilitated via the absorption of positively charged proteins from biological fluids, which intermediate adhesion between cell membrane and $\mathrm{TiO}_{2}$ nanotubes, both negatively charged. ${ }^{37}$ Gongadze et al. showed that fibronectin binding is enhanced on the sharp edges of the $\mathrm{TiO}_{2}$ nanotubes, where negative surface charge density is increased ${ }^{39}$ A number of studies have emphasized the positive effect of a smaller nanotube diameter on osteoblast-like cell adhesion, ${ }^{33,34,45,46}$ while other studies reported opposite findings. ${ }^{47,48}$ Therefore, it is necessary to elucidate the mechanism and size-dependent cell behaviour on surfaces with different $\mathrm{TiO}_{2}$ nanotubes diameter.

Initial protein absorption is followed by integrin binding and the formation of focal adhesion, which are highly organized multiprotein complexes mediating interactions of cells with extracellular matrix, but also acting as mechanosensors which can regulate cell phenotype. ${ }^{49}$ Talin and vinculin have been reported as adaptor proteins associated with the formation and stabilization of focal adhesion complexes. As was demonstrated, talin forms the structural core of focal adhesion via an integrin-talin-actin module. Vinculin bound to talin strengthens and stabilizes focal adhesion complexes. ${ }^{49,50}$ In the early stage of an integrin mediated adhesion, transient dot-like focal complexes with $0.5-1 \mu \mathrm{m}$ in diameter were described by Bershadsky et al. ${ }^{51}$ Some of them later mature into focal adhesion $(3-10 \mu \mathrm{m})$ associated with actin cytoskeleton. ${ }^{49}$ Interestingly, $15 \mathrm{~V}$ samples showed lower cell spreading compared to $20 \mathrm{~V}$ samples as well as higher surface roughness which was probably connected with lower filopodia penetration into nanotubes as well as with lower vinculin amount measured by ELISA assay. This can be affected not only by the nanotube diameter, but also their distance and length. Several in vitro studies have demonstrated an increased vinculin amount on $\mathrm{TiO}_{2}$ nanotube-based surfaces. Dense vinculin positive areas were observed using immunohistochemistry on a nanoporous surface, together with a higher number of focal adhesions, compared to Ti control. In this study, vinculin was visualized in a human osteoblast precursor line (OPC1) 5 days after seeding on nanotubes, with an internal diameter of approximately $51 \mathrm{~nm}$ and $600 \mathrm{~nm}$-long created by anodic oxidation at $20 \mathrm{~V}^{44}$ Similarly, Filova $e t$ al. presented an increasing talin and vinculin concentration with increased nanotube diameter created on Ti6Al4V by anodic oxidation. Vinculin and talin were visualized in osteoblasts 3 days after seeding, where the highest concentration was observed on nanotubes with an average inside diameter of $79 \mathrm{~nm}(30 \mathrm{~V}) .^{36}$ Similarly, Saha et al. presented diffused dot-like cytoplasmic vinculin visualized in MG63 osteoblasts cultured for $60 \mathrm{~h}$ on various nanostructured Ti6Al4V surfaces. Colocalization of F-actin with vinculin was only documented on polished titanium. Moreover, an increase in the cell area was found on nanotubes with a diameter in the range of $25-55 \mathrm{~nm}$ in comparison with the smooth Ti6Al4V..$^{52}$ These findings correspond with our results from vinculin and talin 

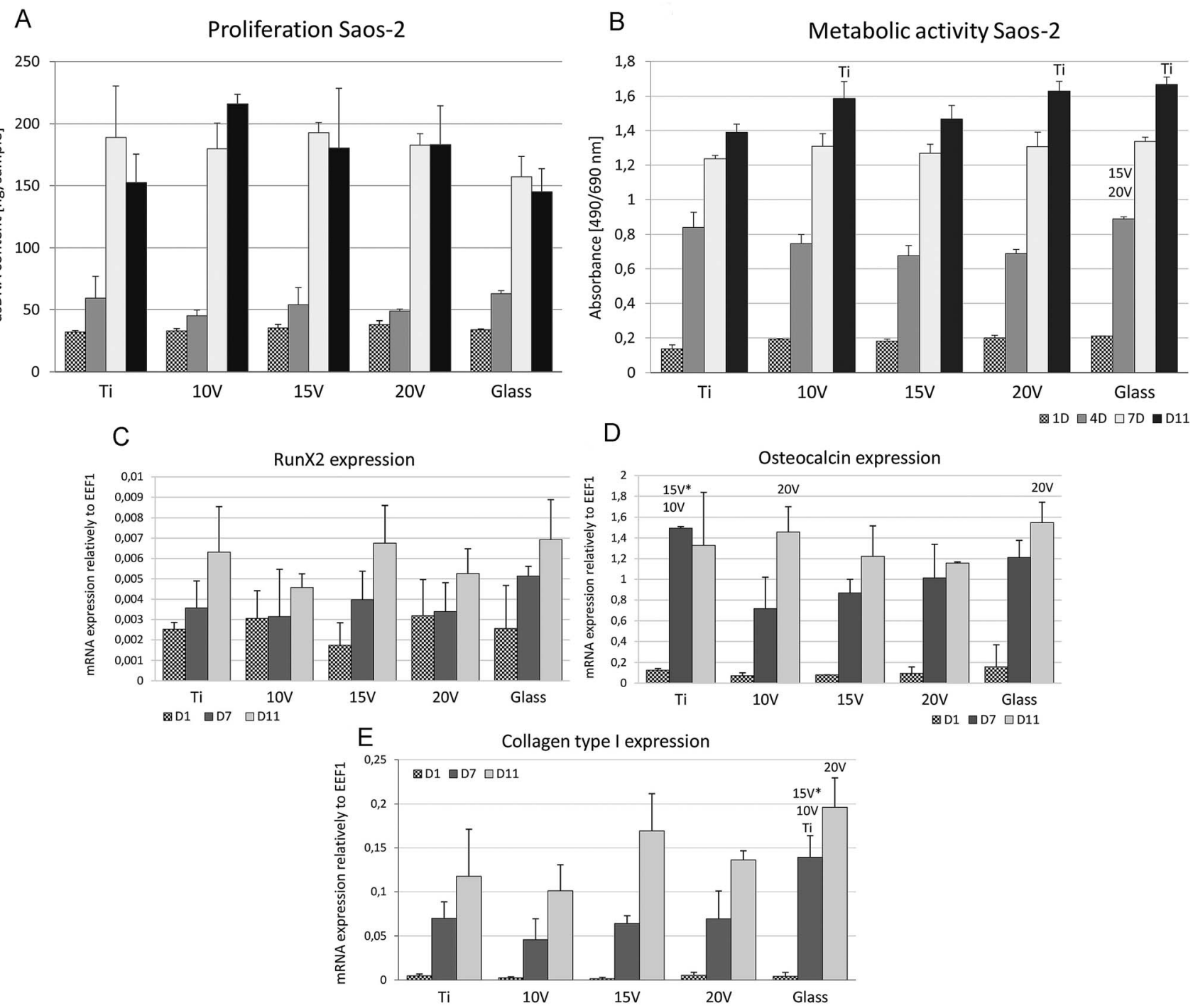

Fig. 5 Proliferation (A), metabolic activity (B) and osteogenic differentiation (C-E) of human Saos-2 osteoblast-like cells cultured on untreated and differently nanostructured cpTi samples. Untreated cpTi (Ti), differently nanostructured cpTi samples by anodic oxidation at $10 \mathrm{~V}, 15 \mathrm{~V}, 20 \mathrm{~V}$ and control glass. Day (D), no significant differences were observed in the cell proliferation. (B) $P$ values $<0.05$ (marked by group name) considered significant versus samples labelled above columns. (C-E) Relative expression of RunX2 mRNA (C), relative expression of osteocalcin mRNA (D), relative expression of osteocalcin mRNA (E) $P$ values $<0.01$ (marked by group name) and $<0.005$ (marked as name of the group with a star) considered significant versus samples labelled above columns.

visualization on nanostructured cpTi samples following $24 \mathrm{~h}$ of culture. A significantly higher concentration of vinculin, determined by ELISA, was on the $20 \mathrm{~V}$ samples compared to the smooth Ti and the specimens with a smaller nanotube diameter. This indicates a strong cell adhesion, thanks to the stabilization effect of vinculin on focal adhesion complexes. ${ }^{49,50}$ The highest amount of talin was found on glass, and, surprisingly, a significantly lower concentration of talin was detected by ELISA at $20 \mathrm{~V}$ compared to other cpTi samples. Furthermore, among nanostructured surfaces the highest talin amount was at $15 \mathrm{~V}$ with an average nanotube diameter of $43 \pm 9 \mathrm{~nm}$. However, this does not have a negative effect on the number of adhered cells on the samples and their metabolic activity on day 1. A possible explanation for this is that nanotubes with a diameter between 24-43 $\mathrm{nm}$ are more appropriate for integrin binding and initial formation of focal adhesion, whereas larger nanotubes stimulate focal adhesion maturation and stabilization by vinculin. Further studies are needed to clarify the early stages of focal adhesion maturation on different diameters of $\mathrm{TiO}_{2}$ nanotubes, as most of the previous studies investigated vinculin and talin concentrations on day 3 or later after cell seeding. ${ }^{36,44,53}$ The formation of focal adhesion is closely connected to cell differentiation and can dramatically influence implant stability. ${ }^{\mathbf{4 4 , 4 6}}$ In general, $\mathrm{TiO}_{2}$ nanotubes prepared by anodic oxidation, have become an effective approach in the stimulation of cell differentiation, but the cell response can vary. Several in vitro studies have demonstrated that nanotubes with a diameter between 15-30 nm supported cell adhesion and spreading, 


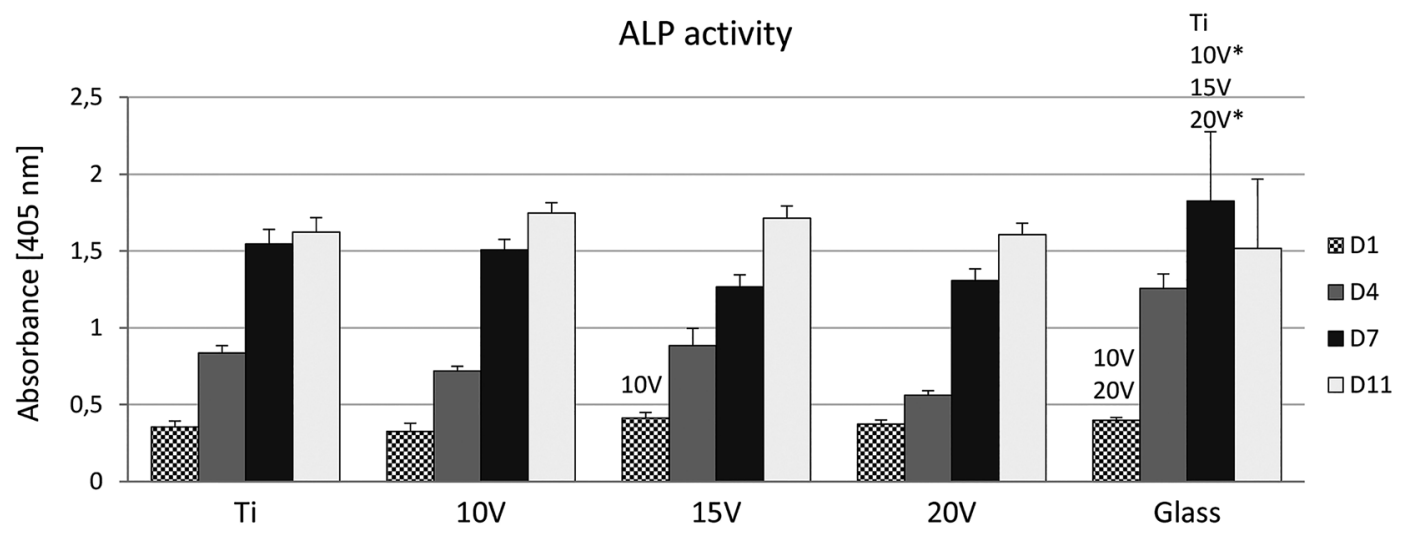

Fig. 6 Alkaline phosphatase activity of human Saos-2 osteoblast-like cells cultured on untreated and differently nanostructured cpTi samples. Untreated $\mathrm{cpTi}(\mathrm{Ti})$, differently nanostructured $\mathrm{cpTi}$ samples by anodic oxidation at $10 \mathrm{~V}, 15 \mathrm{~V}, 20 \mathrm{~V}$ and control glass. $P$ values $<0.05$ (marked by group name) and $<0.01$ (marked as name of the group with a star) considered significant versus samples labelled above.

while a larger diameter of $70-100 \mathrm{~nm}$ supported osteogenic differentiation, but in some cases caused apoptosis. . $^{33,34,54}$

On the contrary, Filova et al. presented enhanced levels of focal adhesion proteins in Saos-2 osteoblasts on nanotubes with a diameter of $79 \mathrm{~nm}$, while smaller nanotubes $(18 \mathrm{~nm}$ and $43 \mathrm{~nm}$ in diameter) enhanced osteocalcin and osteopontin synthesis, but decreased collagen type I synthesis. ${ }^{36}$ A faster initial adhesion and enhanced differentiation of primary rat osteoblasts on $\mathrm{TiO}_{2}$ nanotubes was reported, whereas the fastest adhesion was observed on nanotubes with a diameter of $170 \mathrm{~nm}$ compared to flat titanium and $50 \mathrm{~nm}$ nanotubes. ${ }^{47}$ Therefore, for design of future nanostructure-based bone implants it is important to elucidate a correlation between nanotube diameter and specific cell response.

Interestingly in this study, no significant changes in cell proliferation were observed among all titanium surfaces, which
A

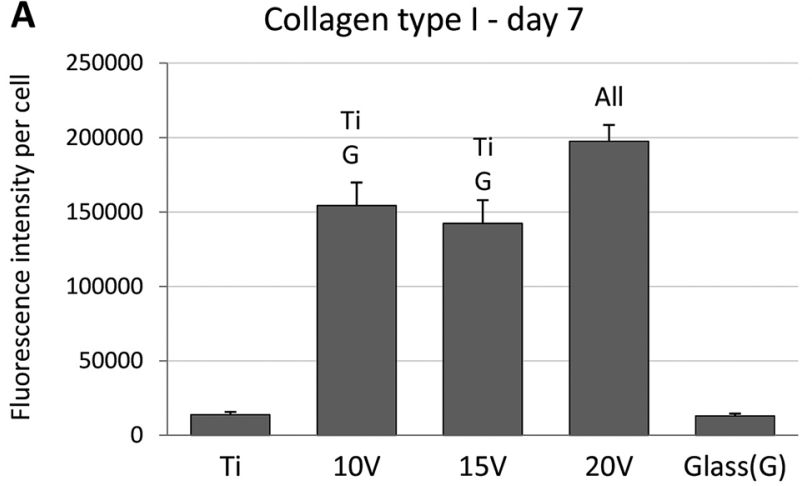

B

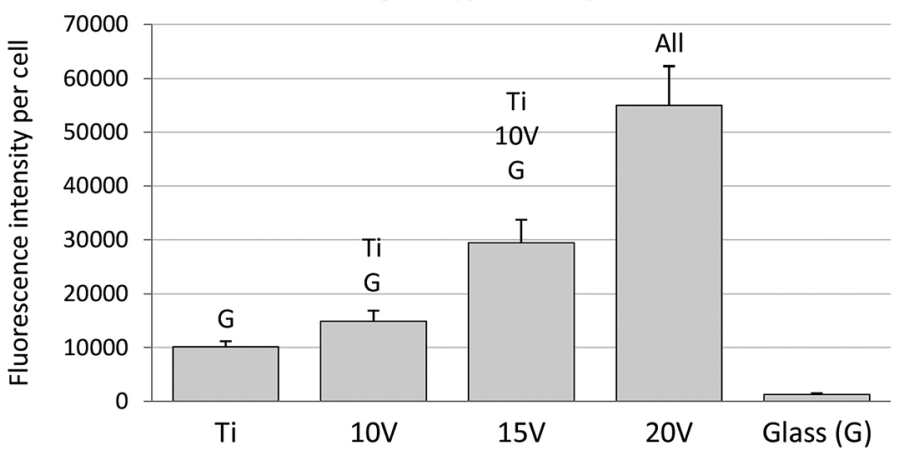

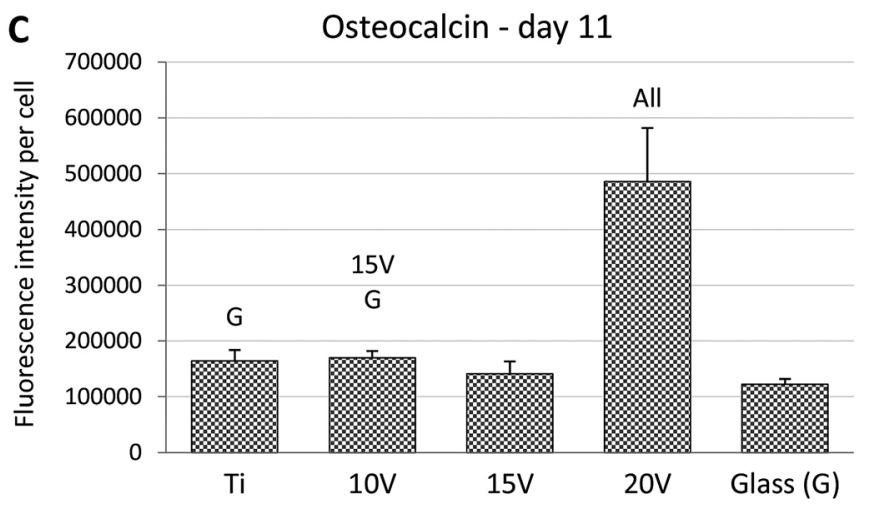

Fig. 7 Detection of collagen type I (A and B) and osteocalcin (C) in human Saos-2 osteoblast-like cells cultured on untreated cpTi (Ti), differently nanostructured cpTi scaffolds by anodic oxidation at $10 \mathrm{~V}, 15 \mathrm{~V}, 20 \mathrm{~V}$ and control glass (G). Data shown as collagen type I and osteocalcin fluorescence intensity calculated from photomicrographs. Day (D), $P$ values $<0.05$ (marked by group name) considered significant versus samples labelled above columns. 

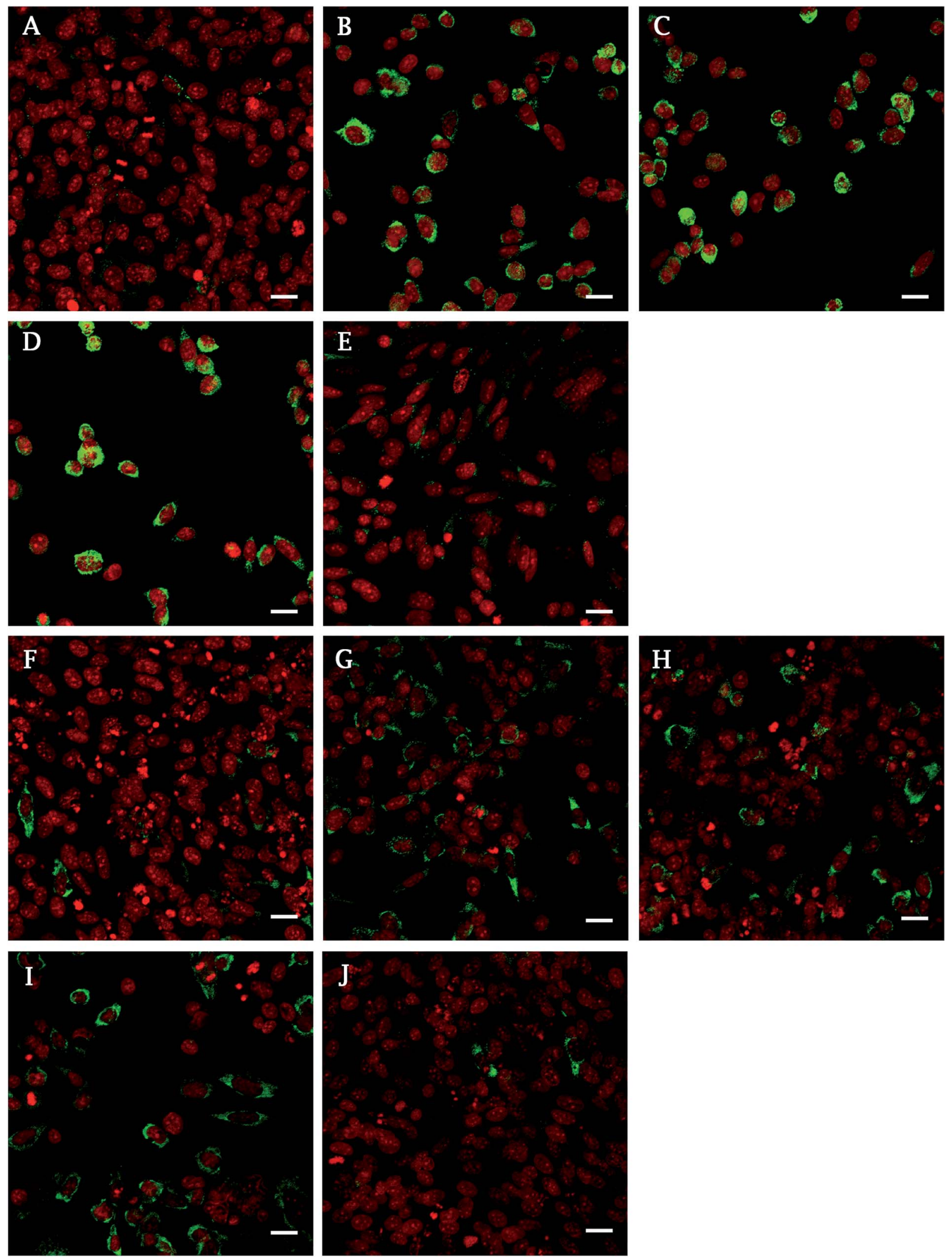

Fig. 8 Immunohistochemical staining of collagen type I in Saos-2 cells cultured on untreated cpTi and differently nanostructured cpTi scaffolds on day $7(\mathrm{~A}-\mathrm{E})$ and day $11(\mathrm{~F}-\mathrm{J})$ of culture. Collagen type I (green) and propidium iodide staining (cell nuclei, red), untreated $\mathrm{cpTi}(\mathrm{A}$ and $\mathrm{F}$ ), $\mathrm{cpTi}$ modified by anodic oxidation at $10 \vee(B$ and $G), 15 \vee(C$ and $H), 20 \vee(D$ and $I)$ and control glass (E and J). Objective $20 \times$, magnification $2 \times$, scale bar $20 \mu \mathrm{m}$. 

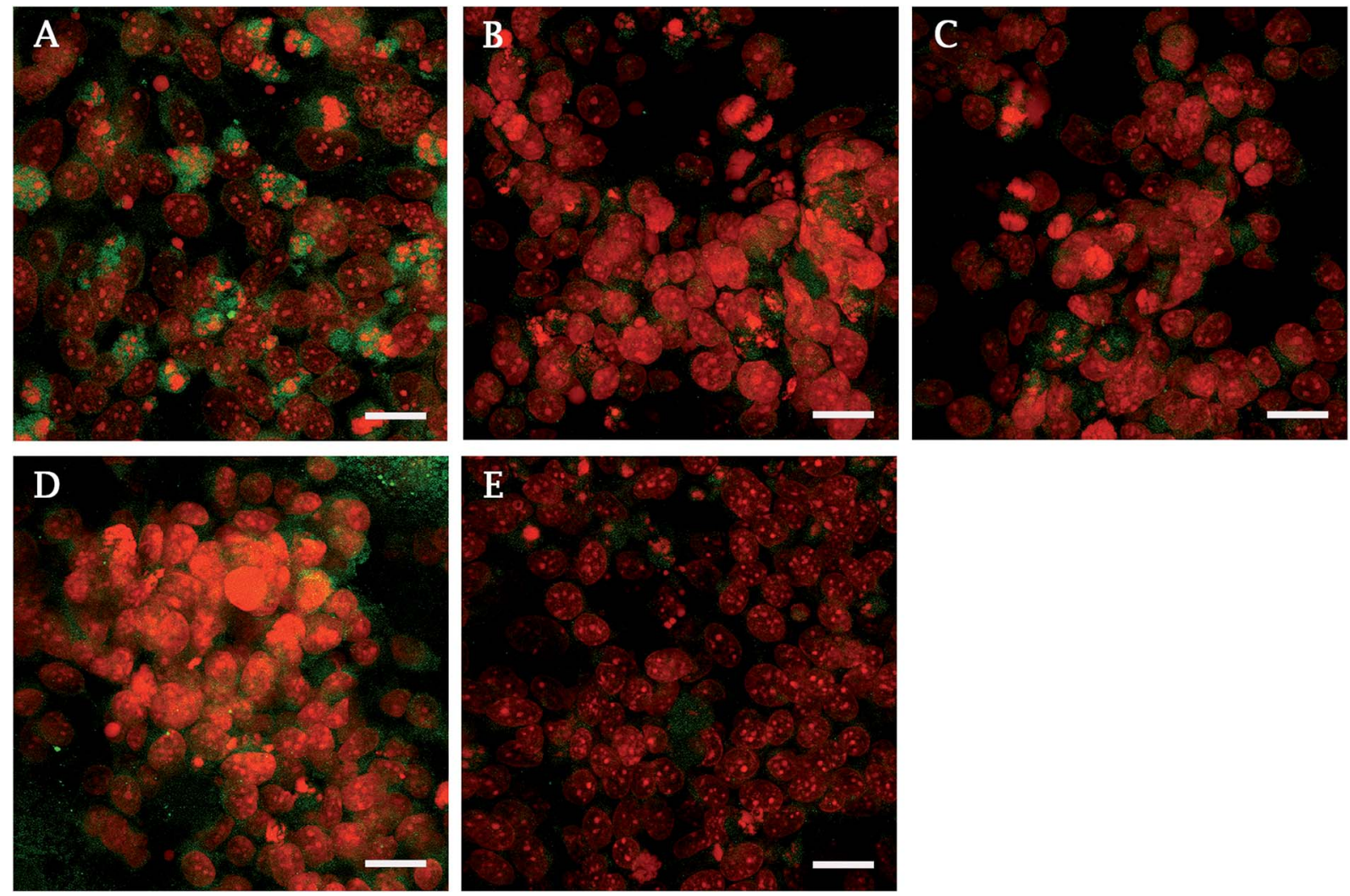

Fig. 9 Immunohistochemical staining of osteocalcin (green) and propidium iodide staining (cell nuclei, red) in human osteosarcoma cells Saos-2 cultured on untreated cpTi (A), cpTi modified by anodic oxidation at $10 \mathrm{~V}(\mathrm{~B}), 15 \mathrm{~V}(\mathrm{C}), 20 \mathrm{~V}$ (D) and control glass (E) on day 11. Objective 40x, magnification $1 \times$, scale bar $20 \mu \mathrm{m}$, immerse oil.

relates to a high biocompatibility of the samples. However, the cell metabolic activity of $10 \mathrm{~V}$ and $20 \mathrm{~V}$ was higher than the smooth cpTi on day 11. Even so, we presented an enhanced synthesis of osteogenic markers (osteocalcin, collagen type I) on nanotubes with an average diameter of $66 \mathrm{~nm}(20 \mathrm{~V})$. During the cell culture, the cell number increased significantly. Fluorescence measurement of type I collagen and osteocalcin was calculated as relative per cell so the total values decreased in all samples but was still the highest in $20 \mathrm{~V}$ samples. Moreover, the higher density of cells supports collagen production even in $\mathrm{Ti}$ samples and glass; therefore, after longer culture the differences are lower compared to day 7. As osteocalcin is a late marker of differentiation, the higher amount is visible after a longer cell culture. Our aim was to visualize the enhancement of osteocalcin synthesis in the samples. We have tested fluorescence intensity on day 11 , and we have found small amounts in all samples as seen in Fig. 7. In addition, the alkaline phosphatase (ALP) activity, RunX2 and osteocalcin mRNA expression rose during 11 days of the Saos-2 cultivation on nanostructured cpTi samples. Our data from the intensity of collagen type I and osteocalcin correspond with the statement that osteoblasts initiate a higher expression of osteogenic markers on nanoporous surfaces compared to smooth control titanium. ${ }^{44}$

Simultaneously, Lv et al. demonstrated that $\mathrm{TiO}_{2}$ nanotubes fabricated by anodic oxidation with a diameter of $70 \mathrm{~nm}$ enhance ALP activity, RunX2 and osteocalcin expression in human adipose derived stem cells, compared to $50 \mathrm{~nm}$ and $100 \mathrm{~nm}$. Along with this, the authors described that the epigenetic mechanism of osteogenic differentiation is mediated through the upregulating methylation of histone $\mathrm{H} 3$ at lysine 4, in the promoter region of osteogenic genes RunX and osteocalcin. ${ }^{38} \mathrm{~A}$ higher osteogenic differentiation was also described in rat osteoblasts cultured on $70 \mathrm{~nm}$ nanotubes compared to control titanium. ${ }^{55,56}$ Furthermore, Yu et al. showed that small nanotubes $(30 \mathrm{~nm})$ enhance cell adhesion in normal conditions, but in an oxidative stress microenvironment larger nanotube diameters $(110 \mathrm{~nm})$ are superior for cell adhesion, differentiation and oxidative stress protection than small nanotubes and native Ti. ${ }^{56}$ Another research group compared osteogenic differentiation potential (in vitro) and osseointegration (in vivo) of titanium implants with large $(90 \mathrm{~nm})$ and small (30 $\mathrm{nm}$ ) inside nanotube diameter created by anodization at $20 \mathrm{~V}$ and $10 \mathrm{~V}$. In vivo experiments on rats showed an improved osseointegration and bone formation on large nanotube implants 2 weeks after implantation into tibia. They also revealed the mechanism of osteogenic differentiation through focal adhesion kinase/Ras homolog gene family member A/yesassociated protein signalling cascade in the MC3T3-E1 osteoblastic cell line, which was greater on implants with a larger nanotube diameter. ${ }^{46}$ As previously described, the beneficial effect of nanotube-based titanium implants osseointegration and bio-functionality can be further encouraged by loading 

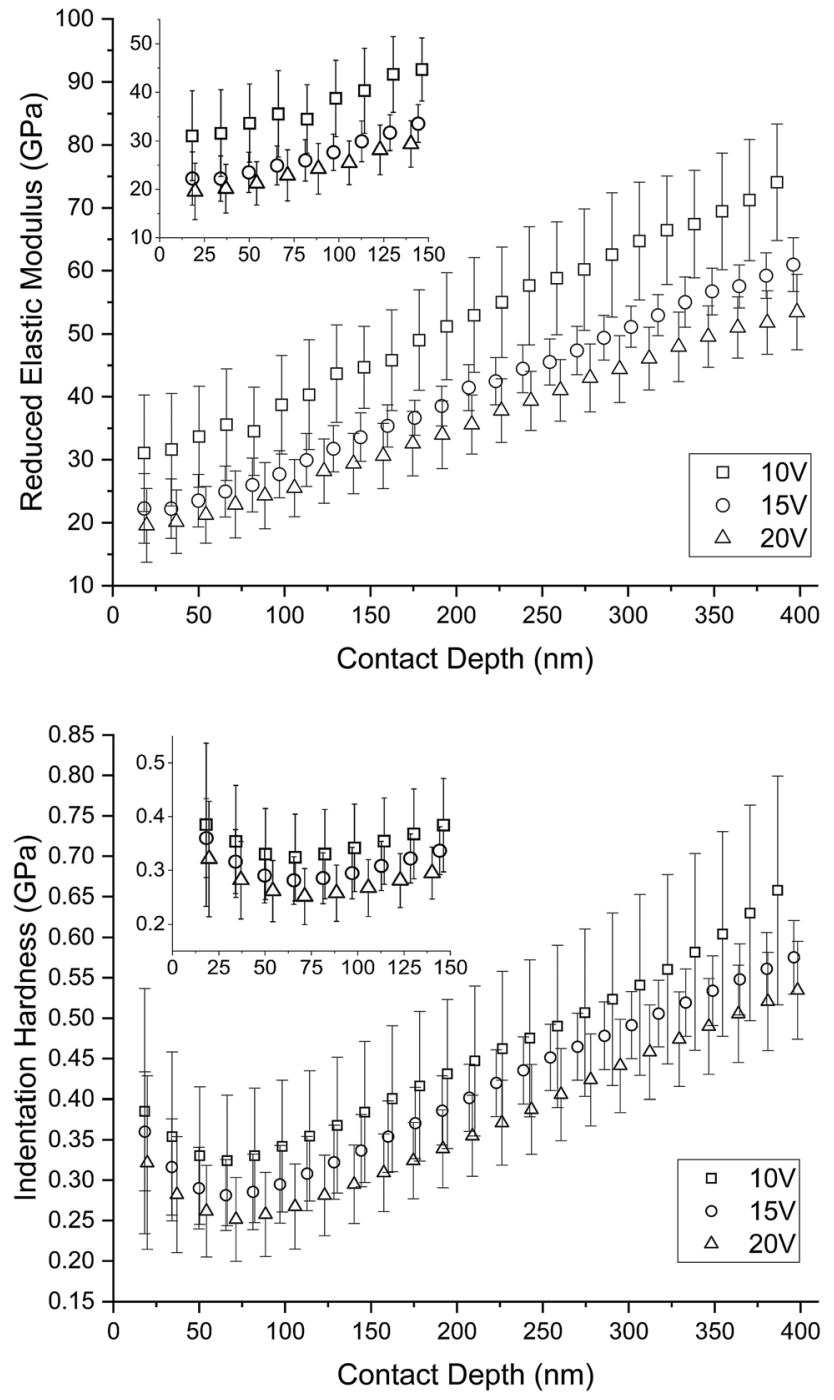

Fig. 10 Depth profiles of mechanical properties differently nanostructured $\mathrm{cpTi}$. There is clearly visible influence of porosity on graphs. Mechanical properties decrease with increasing porosity. Based on rule the 1/10 and length of nanotubes in the Table 2 we can accept measured data up to the contact depth $h_{\mathrm{c}}=46.7 \pm 2.4 \mathrm{~nm}$ for $10 \mathrm{~V}, h_{\mathrm{c}}$ $=73.1 \pm 3.2 \mathrm{~nm}$ for $15 \mathrm{~V}$ and $h_{\mathrm{c}}=109.7 \pm 7.5 \mathrm{~nm}$ for $20 \mathrm{~V}$.

nanotubes with bioactive molecules such as peptides, growth factors, antibacterial substances, nanoparticles or hydroxyapatite. ${ }^{57,58}$ All of these findings could prove to be very promising for the future biomedical application of nanotube modified body implants.

A problem of the present implants are big differences of mechanical properties between titanium implants and bone. $\mathrm{TiO}_{2}$ nanotubes create interface between bone and bulk cpTi implant. We showed in this study that $\mathrm{TiO}_{2}$ nanotubes reduce this interface by creating gradient transition. Thus, the cells are in contact with biocompatible material of same stiffness as an osteointegrating bone..$^{59-61}$ The stiffness increased toward to bulk cpTi material. We can assume that by removing the mechanically incompatible transition we extend the life of the implant by limiting the micro-motions occurring on the ramp change of stiffness at the interface between bone and bulk

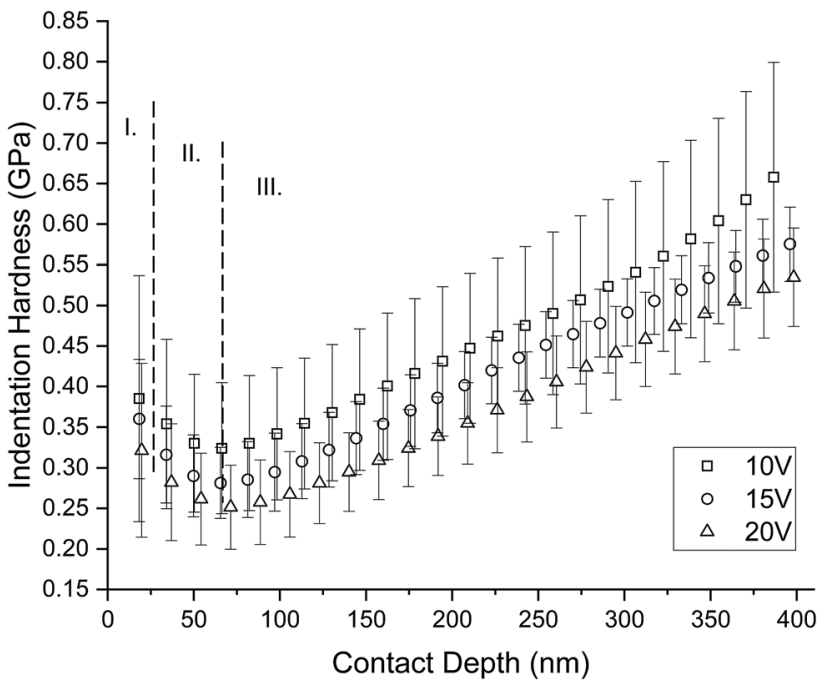

Fig. 11 Depth profile of hardness. Zone I: initial compression of nanotubes in axial direction. Zone II: combination of compression and lateral bending of nanotubes. Zone III: combination of densification and influence of substrate.

titanium. ${ }^{62}$ As similar hardness trends (Fig. 11) were observed by Crawford et al. 2007 and Xu et al. 2015. ${ }^{63,64}$ In our work, we used Berkovich indenter with $100 \mathrm{~nm}$ radius of the tip and our nanotubes had diameters from $24 \pm 5$ to $66 \pm 14 \mathrm{~nm}$; therefore, the deformation mechanism combines both Berkovich and spherical indentation processes from Xu et al. 2015. In our case of probe radius and nanotubes diameters, we can consider our Berkovich probe as spherical in shallow depths (Zone I). Analogically to Xu 2015, Zone I: initial compression of nanotubes in axial direction; Zone II: combination of compression and lateral bending of nanotubes; Zone III: combination of densification and influence of substrate (Fig. 11). Initial compression of upstanding nanotubes appears to be more resistive to the load (Zone 1) than penetration in to bended nanotubes at later stage (Zone 2).

In conclusion, our study herewith confirmed the findings regarding the positive effect of nanostructured titanium surface morphology on osteoblast like cell adhesion and differentiation. We suggest that nanotubes with a diameter of around $66 \mathrm{~nm}$ created by anodic oxidation can increase the osseointegration potential of titanium implants. The study also highlights the benefits of nanotube-based titanium bone implants, which could reduce healing time through better osteoblasts attachment, differentiation and growth.

\section{Conclusions}

In this study, $\mathrm{TiO}_{2}$ nanotubes with a diameter in the range of 24-66 nm were produced on cpTi using anodic oxidation at $10 \mathrm{~V}, 15 \mathrm{~V}$ and $20 \mathrm{~V}$ in fluorine-containing electrolyte. We reported that with higher applied voltage, the length and diameter of the nanotubes increased. Moreover, the higher diameter of nanotubes showed lower elastic modulus and indentation hardness. The human osteoblast like cell culture (Saos-2) 
indicated that the presence of nanotubes support cell adhesion, moreover the nanostructured surface leads to deeper anchoring of the cells and flatter morphology. Both cell proliferation and metabolic activity assays showed good biocompatibility of all the tested cpTi surfaces. Early osteogenic markers, alkaline phosphates activity and RunX2 expression, did not differ among the cpTi samples, and ALP activity was increasing in all samples. Fluorescence confocal microscopy indicated dot like structures of focal adhesive molecules with the highest concentration of vinculin and talin on the $20 \mathrm{~V}$ samples. Similarly, the synthesis of collagen and osteocalcin increased on the nanostructured cpTi, while $20 \mathrm{~V}$ showed the highest synthesis of both collagen type I and osteocalcin. The best results in cell response were achieved on the nanostructured cpTi at $20 \mathrm{~V}$, which support Saos-2 proliferation and osteogenic differentiation. In conclusion, $\mathrm{TiO}_{2}$ nanotubes with a diameter close to $66 \mathrm{~nm}$ showed the highest benefit in vitro and therefore anodic oxidation at $20 \mathrm{~V}$ could be applied to improve bone implants osseointegration. It is expected that this study will be helpful in the future development of appropriate nanotube-based titanium implants.

\section{Conflicts of interest}

There are no conflicts to declare.

\section{Acknowledgements}

Contributions of the authors: data analysis \& collection, in vitro experiments, manuscript preparation: BV; SEM analysis \& samples preparation, manuscript preparation: VH, JF, LJ; microphotographs analysis: MR; qPCR: VS, VB; SEM of cells: VL; ELISA: KV, study design, data interpretation, sample preparation: $\mathrm{MD}$; in vitro experiments planning, confocal microscopy, manuscript preparation: EF. This study was supported by the Czech Science Foundation, Project No. 16-14758S.

\section{References}

1 M. Longand and H. J. Racks, Biomaterials, 1998, 19, 16211639.

2 T. Okabe and H. Hero, Cells Mater., 1995, 5, 211-230.

3 E. P. Su, D. E. Justin, C. R. Pratt, V. K. Sarin, V. S. Nguyen and S. Oh, Bone Joint J., 2018, 100B, 9-16.

4 L. Salou, A. Hoornaert, G. Louarn and P. Layrolle, Acta Biomater., 2015, 11, 494-502.

5 L. M. Bjursten, L. Rasmusson, S. Oh, G. C. Smith, K. S. Brammer and S. Jin, J. Biomed. Mater. Res., Part A, 2010, 92A, 1218-1224.

6 K. C. Popat, L. Leoni, C. A. Grimes and T. A. Desai, Biomaterials, 2007, 28, 3188-3197.

7 H. Tang, Y. Li, J. W. Ma, X. Zhang, B. Li, S. Liu, F. Dai and X. Zhang, Bio-Med. Mater. Eng., 2016, 27, 485-494.

8 T. J. Levingstone, N. Barron, M. Ardhaoui, K. Benyounis, L. Looney and J. Stokes, Surf. Coat. Technol., 2017, 313, 307-318.
9 G. Balasundaram, D. M. Storey and T. J. Webster, Int. J. Nanomed., 2015, 10, 527-535.

10 J. Z. Hao, Y. Li, B. E. Li, X. Wang X, H. Li, S. Liu, C. Lian and H. Wang, Appl. Biochem. Biotechnol., 2017, 183, 280-292.

11 T. P. Queiroz, R. S. de Molon, F. A. Souza, R. Margonar, A. H. Thomazini, A. C. Guastaldi and E. Hochuli-Vieira, Clinical Oral Investigations, 2017, 21, 685-699.

12 J. Bonse, S. V. Kirner, M. Griepentrog, D. Spaltmann and J. Krüger, Materials, 2018, 11, 801.

13 M. Kheradmandfard, S. F. Kashani-Bozorg, C. L. Kim, A. Z. Hanzaki, Y. S. Pyoun, J. H. Kim, A. Amanov and D. E. Kim, Ultrason. Sonochem., 2017, 39, 698-706.

14 N. B. Li, S. J. Sun, H. Y. Bai, G. Y. Xiao, W. H. Xu, J. H. Zhao, X. Chen, Y. P. Lu and Y. L. Zhang, Nanotechnology, 2018, 29, 045101.

15 V. S. Shin, I. K. Yoon, G. S. Lee, W. C. Jang, J. C. Knowles and H. W. Kim, J. Tissue Eng., 2011, 2011, 674287.

16 H. S. Ahn, J. Y. Hwang, M. S. Kim, J. Y. Lee, J. W. Kim, H. S. Kim, U. S. Shin, J. C. Knowles, H. W. Kim and J. K. Hyun, Acta Biomater., 2015, 13, 324-334.

17 V. Zwilling, M. Aucouturier and E. Darque-Ceretti, Electrochim. Acta, 1999, 45, 921-929.

18 P. Roy, S. Berger and P. Schmuki, Angew. Chem., Int. Ed., 2011, 50, 2904-2939.

19 S. Minagar, J. Wang, C. C. Berndt, E. P. Ivanova and C. Wen, J. Biomed. Mater. Res., Part A, 2013, 101, 2726-2739.

20 Q. Wang, J. Y. Huang, H. Q. Li, A. Z. Zhao, Y. Wang, K. Q. Zhang, H. T. Sun and Y. K. Lai, Int. J. Nanomed., 2016, 12, 151-165.

21 D. Ionita, D. Bajenaru-Georgescu, G. Totea, A. Mazare, P. Schmuki and I. Demetrescu, Int. J. Pharm., 2017, 517, 296-302.

22 W. W. Liu, P. L. Su, S. Chen, N. Wang, Y. Ma, Y. Liu, J. Wang, Z. Zhang, H. Li and T. J. Webster, Nanoscale, 2014, 6, 90509062.

23 N. Esfandiari, A. Simchi and R. Bagheri, J. Biomed. Mater. Res., Part A, 2014, 102, 2625-2635.

24 M. Niinomi and M. Nakai, Int. J. Biomater., 2011, 836587.

25 G. Crawford, N. Chawla, K. Das, S. Bose and A. Bandyopadhyay, Acta Biomater., 2007, 3, 359-367.

26 R. M. Alice, Fluorescent Image Analyser (ver 1.0), software available at http://alice.fbmi.cvut.cz.

27 P. Vlcak, F. Cerny, J. Drahokoupil, J. Sepitka and Z. Tolde, J. Alloys Compd., 2015, 620, 48-54.

28 P. Vlcak, J. Sepitka, J. Drahokoupi, T. Horazdovsky and Z. Tolde, J. Nanomater., 2016, 2016, 1-7.

29 W. C. Oliver and G. M. Pharr, J. Mater. Res., 1992, 7, 15641583.

30 ISO 14577-4: 2007, Metallic materials - Instrumented indentation test for hardness and materials parameters - Part 4: Test method for metallic and non-metallic coatings.

31 J. M. Cordeiro, T. Beline T, A. L. R. Ribeiro, E. C. Rangel, N. C. da Cruz, R. Landers, L. P. Faverani, L. G. Vaz, L. M. G. Fais, F. B. Vicente, C. R. Grandini, M. T. Mathew, C. Sukotjo and V. A. R. Barão, Dent. Biomater., 2017, 33, 1244-1257. 
32 P. Vlcak, J. Drahokoupil, P. Vertat, J. Sepitka and J. Duchon, J. Alloys Compd., 2018, 746, 490-495.

33 K. S. Brammer, S. Oh, C. J. Cobb, L. M. Bjursten, H. van der Heyde and S. Jin, Acta Biomater., 2009, 5, 3215-3223.

34 S. Oh, K. S. Brammer, S. J. Li, D. Teng, A. J. Engler, S. Chien and S. Jin, Proc. Natl. Acad. Sci. U. S. A., 2009, 106, 2130-2135.

35 T. Shokuhfar, A. Hamlekhan, J. Y. Chang, C. K. Choi, C. Sukotjo and C. Friedrich, Int. J. Nanomed., 2014, 9, 3737-3748.

36 E. Filova, J. Fojt, M. Kryslova, H. Moravec, L. Joska and L. Bacakova, Int. J. Nanomed., 2015, 10, 7145-7163.

37 M. Kulkarni, A. Mazare, E. Gongadze, Š. Perutkova, V. KraljIglič, I. Milošev, P. Schmuki, A. Iglič and M. Mozetič, Nanotechnology, 2015, 26, 062002.

38 L. W. Lv, Y. S. Liu, P. Zhang, X. Zhang, J. Liu, T. Chen, P. Su, H. Li and Y. Zhou, Biomaterials, 2015, 39, 193-205.

39 E. Gongadze, D. Kabaso, S. Bauer, T. Slivnik, P. Schmuki, U. van Rienen and A. Iglič, Int. J. Nanomed., 2011, 6, 18011816.

40 A. Tian, X. F. Qin, A. H. Wu, H. Zhang, Q. Xu, D. Xing, H. Yang, B. Qiu, X. Xue, D. Zhang and C. Dong, Int. J. Nanomed., 2015, 10, 2423-2439.

41 H. J. Hausser and R. E. Brenner, RSC Adv., 2005, 333, 216222.

42 E. M. Czekanska, M. J. Stoddart, J. R. Ralphs, R. G. Richards and J. S. Hayes, J. Biomed. Mater. Res., Part A, 2014, 102, 2636-2643.

43 E. M. Czekanska, M. J. Stoddart, R. G. Richards and J. S. Hayes, Eur. Cells Mater., 2012, 24, 1-17.

44 K. Das, S. Bose and A. Bandyopadhyay, J. Biomed. Mater. Res., Part A, 2009, 90, 225-237.

45 J. Park, S. Bauer, K. A. Schlegel, F. W. Neukam, K. von der Mark and P. Schmuki, Small, 2009, 5, 666-671.

46 H. Zhang, L. F. Cooper, X. N. Zhang, Y. Zhang, F. Deng, J. L. Song and S. Yang, RSC Adv., 2016, 6, 44062-44069.

47 Y. Zhang, R. Luo, J. Tan J, J. X. Wang, X. Lu, S. X. Qu, J. Weng and B. Feng, Regener. Biomater., 2017, 4, 81-87.

48 R. Zhang, H. Wu, J. Ni, C. Zhao, Y. Chen, C. Zheng and X. Zhang, Mater. Sci. Eng., C, 2015, 53, 272-279.
49 S. Di Cio and J. E. Gautrot, Acta Biomater., 2016, 30, 26-48. 50 J. R. Liu, Y. L. Wang, W. I. Goh, H. Goh, M. A. Baird, S. Ruehland, S. Teo, N. Bate, D. R. Critchley, M. W. Davidson and P. Kanchanawong, Proc. Natl. Acad. Sci. U. S. A., 2015, 112, E4864-E4873.

51 A. D. Bershadsky, C. Ballestrem, L. Carramusa, Y. Zilberman, B. Gilquin, S. Khochbin, A. Y. Alexandrova, A. B. Verkhovsky, T. Shemesh and M. M. Kozlov, Eur. J. Cell Biol., 2006, 85, 165-173.

52 S. Saha, R. Kumar, K. Pramanik and A. Biswas, Appl. Surf. Sci., 2018, 449, 152-165.

53 H. Moravec, M. Vandrovcova, K. Chotova, J. Fojt, E. Pruchova, L. Joska and L. Bacakova, Mater. Sci. Eng., C, 2016, 65, 313-322.

54 J. Park, S. Bauer, K. von der Mark and P. Schmuki, Nano Lett., 2007, 7, 1686-1691.

55 M. Lai, Z. Y. Jin and Z. G. Su, Mater. Sci. Eng., C, 2017, 73, 490-497.

56 Y. Yu, X. Shen, Z. Luo, Y. Hu, M. Li, P. Ma, Q. Ran, L. Dai, Y. He and K. Cai, Biomaterials, 2018, 167, 44-57.

57 A. Roguska, M. Pisarek, A. Belcarz, L. Marcon, M. Holdynski, M. Andrzejczuk and M. Janik-Czachor, Appl. Surf. Sci., 2016, 388(part B), 775-785.

58 W. F. Oliveira, I. R. S. Arruda, G. M. M. Silva, G. Machado, L. C. B. B. Coelho and M. T. S. Correia, Mater. Sci. Eng., C, 2017, 81, 597-606.

59 F. Butz, H. Aita, C. J. Wang and T. Ogawa, J. Dent. Res., 2006, 85, 560-565.

60 R. Korsa, J. Lukes, J. Sepitka and T. Mares, J. Biomech. Eng., 2015, 137, 081002.

61 D. Wu, P. Isaksson, S. J. Ferguson and C. Persson, Acta Biomater., 2018, 78, 1-12.

62 T. Sugiura, K. Yamamoto, S. Horita, K. Murakami and T. Kirita, Clin. Implant Dent. Relat. Res., 2018, 20, 43-49.

63 G. Crawford, N. Chawla, K. Das, S. Bose and A. Bandyopadhyay, Acta Biomater., 2007, 3, 359-367.

64 Y. Xu, M. Liu, M. Wang, A. Oloyede, J. Bell and C. Yan, J. Appl. Phys., 2015, 118, 145301. 